\title{
SENSORIAMENTO REMOTO ORBITAL PARA MODELAGEM DA EVAPOTRANSPIRAÇÃO: SÍNTESE TEÓRICA E APLICAÇÕES EM COMPUTAÇÃO NA NUVEM
}

\author{
ORBITAL REMOTE SENSING FOR EVAPOTRANSPIRATION MODELING: \\ THEORETICAL OVERVIEW AND APPLICATIONS IN CLOUD COMPUTING ${ }^{\circ}$
}

TELEDETECCIÓN ORBITAL PARA MODELAMIENTO DE LA EVAPOTRANSPIRACIÓN: PANORAMA TEÓRICO Y APLICACIONES EN LA COMPUTACIÓN EN NUBE 8

Recebido em: 01/08/2021 - Aprovado em: 26/10/2021 - Publicado em: 07/11/2021

http://dx.doi.org/10.18011/bioeng2021v15n3p425-468

César de Oliveira Ferreira Silva1 (cesaroliveira.f.silva@gmail.com)

Pedro Henrique Jandreice Magnoni² (pedrohjmagnoni@gmail.com)

Rodrigo Lilla Manzione ${ }^{3}$ (lilla.manzione@unesp.br)

\footnotetext{
1 Universidade de Campinas. Campinas, SP, Brasil.

2 Universidade Estadual Paulista "Júlio de Mesquita Filho". Botucatu, SP, Brasil.

3 Universidade Estadual Paulista "Júlio de Mesquita Filho". Tupã, SP, Brasil.
}

\section{RESUMO}

O objetivo desse artigo de revisão foi compilar os aspectos teóricos e tecnológicos da modelagem de evapotranspiração (ET) baseada em sensoriamento remoto. Levantamos os conceitos termohidrológicos que dão base ao fenômeno da ET, a saber, os fluxos de energia no solo ("termo") e balanço hidrológico. Também apresentamos as principais variantes do conceito de ET. Levantamos os modelos aplicados a imagens de satélite mais difundidos (a serem implementados pelo pesquisador) e apresentamos suas premissas, limitações e oportunidades. Os modelos baseados em sensoriamento remoto são voltados à ET real. Por fim, levantamos bases de dados de ET real já prontas (disponíveis no Google Earth Engine GEE), e, para elas, desenvolvemos painéis interativos para extração desses dados. Com esses painéis é possível extrair facilmente séries temporais de ET real e realizar posteriores calibrações com dados de campos.

Palavras-chave: Agrometeorologia. Hidrologia. Google Earth Engine. Modelagem. Automatização. 


\section{INTRODUÇÃO}

A crescente pressão sobre o uso de recursos hídricos para diversos usos (agricultura, abastecimento público, etc) vem requerendo cada vez mais o conhecimento de onde, quando e como a água está sendo utilizada (SILVA et al., 2019a). Nesse contexto, a evapotranspiração tem recebido grande atenção pela sua relevante importância no balanço hídrico, representando 60 a $80 \%$ do volume de água que retornar para atmosfera (TATEISH, 1996).

Modelar a dinâmica espacial da evapotranspiração tem razoável complexidade, já que é altamente variável no tempo e no espaço (TEIXEIRA, 2010; TUCCI, SILVEIRA, 2015; SILVA et al., 2019a). Essas informações são indispensáveis ao planejamento e manejo de recursos hídricos, principalmente em locais dependentes economicamente da produção agrícola irrigada. Nesse sentido, a utilização de técnicas de sensoriamento remoto orbital para condução de mapeamentos em hidrologia tornou possível um diagnóstico espacial de forma mais barata, rápida, que proporciona ferramentas para o planejamento integrado entre recursos ambientais, agrícolas e sociais em diversas escalas (TEIXEIRA et al., 2013, 2017a, 2016).

O uso conjunto de sensoriamento remoto com dados agrometeorológicos pode melhorar o manejo de água em diferentes escalas espaciais e temporais em agrosecossistemas, podendo-se monitorar o impacto causado pela agrícola intensiva sobre as condições ambientais. Ao ser aplicado conjuntamente com dados agrometeorológicos, o sensoriamento remoto torna-se um instrumento de manejo e gerenciamento da água em larga escala, tanto para agricultura de sequeiro quanto para culturas irrigadas, ou ainda, de recursos hídricos em geral. Com estas ferramentas pode-se fazer um acompanhamento dos impactos das mudanças climáticas e daqueles causados pelas atividades da agropecuária intensiva sobre as condições ambientais e do consumo hídrico incremental das culturas decorrente da substituição da vegetação nativa por culturas agrícolas que afetam os ecossistemas aquáticos e terrestres, intensificando a competição pelos recursos hídricos (SILVA et al., 2018b; SILVA et al., 2019c).

O objetivo desse artigo de revisão foi compilar os aspectos teóricos e tecnológicos da modelagem de evapotranspiração baseada em sensoriamento remoto. A justificativa desse trabalho é a ausência dessa compilação em língua portuguesa, estando esse material, atualmente, fragmentado na literatura cientifica em português. 
A primeira etapa da compilação foi uma pesquisa exploratória para construir uma síntese bibliográfica a respeito dos conceitos termohidrológicos fundamentais para compreensão do fenômeno da evapotranspiração e sua relação com parâmetros obtidos por sensoriamento remoto. Em um segundo momento foi desenvolvido um painel interativo baseado em bancos de dados de estimativas de evapotranspiração, por sensoriamento remoto, disponíveis em uma ferramenta de computação em nuvem.

A Figura 1 apresenta as delimitações da revisão de literatura e o direcionamento tomado para apresentar os aspectos tecnológicos da modelagem da evapotranspiração. Nas seções a seguir apresentamos o detalhamento dessas etapas.

Figura 1 - Panorama da relação entre síntese teórica (baseada nos conceitos termohidrológicos que dão base à evapotranspiração) e as aplicações baseadas em imagens de satélite e as bases de dados prontas no Google Earth Engine (GEE)

\section{Fluxo termohidrológico no sistema água-solo-planta-atmosfera}

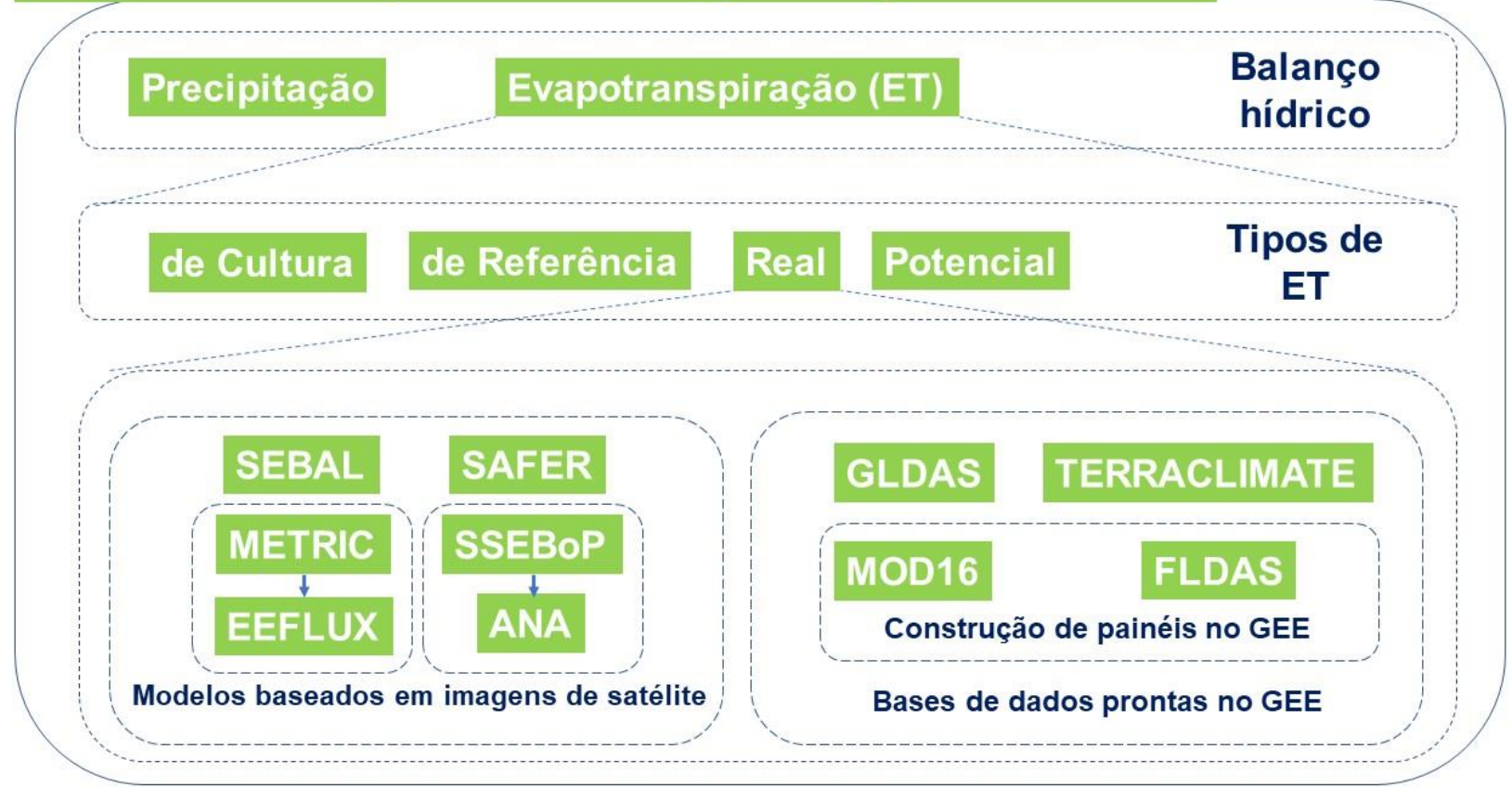

\subsection{PESQUISA EXPLORATÓRIA PARA SÍNTESE TEÓRICA}

A fundamentação teórica foi sintetizada em dois aspectos que, juntos, chamamos de "termohidrológicos", que são a ótica dos fluxos de energia no solo ("termo") e do balanço 
hídrico ("hidrológico"). Complementarmente a esses dois aspectos, apresentamos uma distinção entre os quatro tipos de evapotranspiração mais comuns na literatura, diferenciando-as para qualificar a discussão, que muitas vezes se torna difusa por não definir claramente o tipo de evapotranspiração que está sendo considerada.

A fundamentação tecnológica sintetiza conceitos fundamentais para escolha dos produtos obtidos por sensoriamento remoto orbital. Foram levantadas opções de 1) imageamento nas faixas do espectro visível e infravermelho próximo ou termal para uso em determinados modelos de estimativa de evapotranspiração e 2) bases de dados de evapotranspiração já disponíveis. Foram classificados os principais satélites que provêm dados de sensoriamento remoto, destacando suas limitações e potenciais dentro da suas resoluções espaço-temporais. Privilegiamos as opções públicas (com isso exclui-se dessa revisão os satélites particulares, que demandam pagamento para uso das imagens obtidas) e bancos de dados disponíveis na plataforma Google Earth Engine (GEE) para computação geoespacial na nuvem. Optamos por destacar as premissas, limitações e oportunidades dos modelos baseados de estimativa de evapotranspiração por imagens de satélite e referenciar os artigos com maior aprofundamento da formulação matemática.

\subsection{PESQUISA DE BASES DE DADOS EM COMPUTAÇÃO EM NUVEM}

Grandes bases de dados obtidas por sensoriamento remoto estão disponíveis para análise, mas sua manipulação pode ser difícil por envolver muitos processos manuais (download dos arquivos matriciais, avaliação de compatibilidade desses arquivos com o software utilizado, ajustes de projeção geográfica, dentre outras). Assim, automatizar e/ou otimizar esses processos é essencial para tornar qualquer metodologia reprodutível, já que nesses procedimentos manuais nem sempre todas as configurações são conhecidas pelos pesquisadores independentes que queiram replicá-la.

GEE é uma plataforma de processamento de imagens de satélite em escala global, com bases de dados históricas que podem alcançar mais de 50 anos. Permite aos usuários fazer manipulação geoespacial de imagens digitais em áreas de interesse (por exemplo, o interior de um arquivo vetorial), com posterior download dos resultados finais. Silva (2020) reporta um processamento realizado no GEE, constituído de filtragem de imagens (por percentual de encobrimento por nuvem), recorte da área de estudo, criação de índices de 
vegetação e classificação supervisionada de área irrigada e não irrigada, que teve tempo médio, refeito 10 vezes, de 52 segundos.

\subsubsection{Construção dos painéis em GEE para extração de dados prontos de evapotranspiração real}

O editor de código do GEE foi utilizado para elaboração de três painéis para visualização/extração de séries temporais de produtos e bases com estimativas já calculadas de evapotranspiração baseadas em sensoriamento remoto. As fontes de dados foram os produtos MOD16A2 Version 6 Evapotranspiration/Latent Heat Flux e FLDAS Noah Land Surface Model L4 Global Monthly $0.1 \times 0.1$ degree, com resolução temporal/espacial de 8 dias $/ 250 \mathrm{~m}$, e mensal/0,1 graus, respectivamente.

A Tabela 1 apresenta os links para os painéis desenvolvidos no GEE pelos autores para obter séries temporais de bases de dados de evapotranspiração de diferentes bases de dados. Os painéis estão disponíveis para acesso livre a qualquer usuário (passível de acesso em qualquer navegador de internet). Os códigos-fonte é possível manipular e alterar as ações dos painéis, desde que o usuário tenha uma conta ativa de editor no GEE.

Tabela 1 - Painéis desenvolvidos no GEE para obter a série temporal de bases de dados de estimativas de evapotranspiração por sensoriamento remoto.

\begin{tabular}{c|c|c|c|c}
\hline $\begin{array}{c}\text { Base de } \\
\text { dados }\end{array}$ & $\begin{array}{c}\text { Anos } \\
\text { disponíveis }\end{array}$ & Descrição & Painel & Código \\
\hline MOD16A2 & 2001 -atual & $\begin{array}{r}\text { Visualização e extração dos dados em cobertura } \\
\text { global dentro do período disponível }\end{array}$ & $\underline{\underline{\text { P1 }}}$ & $\underline{\underline{\text { C1 }}}$ \\
\hline FLDAS & 1982 -atual & $\begin{array}{r}\text { Visualização e extração dos dados em cobertura } \\
\text { global dentro do período disponível }\end{array}$ & $\underline{\text { C2 }}$ \\
\hline MOD16A2 $x$ & 2020 & $\begin{array}{c}\text { Comparativo das estimativas de } E T_{A} \text { das duas bases } \\
\text { de dados sob três diferentes coordenadas }\end{array}$ & $\underline{\underline{\text { P3 }}}$ & $\underline{\text { G3 }}$ \\
\hline
\end{tabular}

Consideramos que o uso de ferramentas de computação em nuvem, como o GEE, se tornou fundamental para apoiar esta revisão por pré-processar esses bancos de dados e homogeneizar essas etapas, além de prover maior transparência, já que é possível compartilhar o código desenvolvido de forma pública para a comunidade científica. 


\section{FUNDAMENTAÇÃO TERMOHIDROLÓGICA: BALANÇO HÍDRICO E FLUXO DE ENERGIA NO SOLO}

As camadas mais superficiais de um solo, seus constituintes e suas interações com o meio adjacente são de grande importância para as Ciências Agroambientais: o sistema solo-planta-atmosfera, que também engloba a água presente na zona não saturada do solo e, portanto, é de grande interesse para a Hidrologia (TUCCI, SILVEIRA, 2015). A importância de se conhecer os processos que se desenvolvem nesse sistema está relacionado a temas como poluição ambiental (impacto dos despejos de resíduos sólidos, de rejeitos nucleares e de fertilizantes no solo, salinização do solo e da água subterrânea), recarga de reservatórios de água subterrâneas, avaliação de perdas por evaporação e transpiração da planta, manejo da água para fins de irrigação (lâminas a aplicar, necessidade de rebaixamento do aquífero), dentre outros (CHRISTOFOLETIS, 1999, HEALY, COOK, 2002, BERTONI, LOMBARDI NETO, 2014, KING et al., 2017, SILVA, MEDEIROS, 2017). Para compreender a dinâmica da evapotranspiração dentro do sistema água-solo-planta-atmosfera, vamos apresentar por meio de duas abordagens complementares: pela ótica hidrológica (balanço hídrico) e pela ótica térmica (fluxo de energia no solo).

\subsection{BALANÇO HÍDRICO}

O solo é constituído de uma matriz porosa composta por grãos e por vazios. Esses vazios podem ou não estar preenchidos com água. Sob o ponto de vista de ocorrência de água, o solo pode ser dividido em zona saturada ou zona não saturada. A zona de aeração, ou zona não saturada do solo, é a ligação entre as águas subterrâneas, que caracterizam a zona saturada do solo, e a atmosfera (CHRISTOFOLETIS, 1999). Nessa zona, os vazios entre as partículas do solo são preenchidos por água e ar. O movimento da água na zona não saturada está relacionado com fenômenos como evaporação do solo, retirada da água do solo pelas raízes das plantas (transpiração) (HEALY, COOK, 2002, HEALY, 2010).

O balanço hídrico, em um compartimento vertical definido pode ser escrito em termos de quantidade por área unitária e por unidade de tempo, caracterizando lâminas equivalentes (TUCCI, SILVEIRA, 2015). Usualmente todos os termos da equação que 
representa esse balanço são expressos em milímetros $(\mathrm{mm})$. O balanço, considerando os vários parâmetros possíveis, pode ser expresso na Equação 1, a seguir.

$$
\Delta W=\left(P+I_{r r}+C\right)-(E+T+D+Q+I)
$$

Onde $\Delta W$ é a variação no armazenamento de água no perfil do solo, $P$ a precipitação, $I_{r r}$ a irrigação, $C$ a ascensão capilar, caracterizando o fluxo do aquífero para as camadas superiores adjacentes de menor umidade, $E$ evaporação, $T$ transpiração, $D$ percolação profunda, relacionado ao fluxo alimentador do aquífero, $Q$ escoamento superficial e $I$ água interceptada pelas plantas (CHRISTOFOLETIS, 1999, TUCCI, SILVEIRA, 2015).

A evapotranspiração é a principal saída de água do sistema água-solo-planta para a atmosfera. Este fluxo ocorre através das folhas das plantas pelos estômatos como transpiração $(T)$ e diretamente da superfície do solo como evaporação $(E)$. Os estômatos são pequenas aberturas por onde os gases e o vapor d'água passam. A vaporização ocorre dentro da folha, nos espaços intercelulares sendo a troca de vapor com a atmosfera é controlada pela abertura dos estômatos. Os parâmetros E e T dependem do tipo da cultura, o desenvolvimento das plantas, condições ambientais, manejos culturais e sistemas de irrigação.

Por outro lado, a precipitação e/ou irrigação são os principais fornecedores de água para o sistema água-solo-planta. Os eventos de chuva provêm água para a vegetação e outras superfícies, e começam a infiltrar-se no solo, o que aumenta a umidade do solo e, a partir daí, o excesso de água se infiltra lentamente pela zona intermediária até a zona subsuperficial. A quantidade de umidade que uma área de terra perde por evapotranspiração depende principalmente da incidência da precipitação, em segundo lugar dos fatores climáticos de temperatura, umidade, vento etc. e, em terceiro lugar, do tipo, manejo e extensão da cultura (CHRISTOFOLETIS, 1999, KING et al., 2017). No período seco, quando as taxas de evapotranspiração excedem a umidade disponível da precipitação, a recarga para o lençol freático é menor ou insignificante e assim os níveis de água subterrânea diminuem (CHRISTOFOLETIS, 1999). Um fluxograma esquemático desta dinâmica é apresentado na Figura 1, representando o armazenamento de água na superfície da terra, no dossel da planta, dentro da zona não saturada (zona do solo e subsuperfície) e nas águas subterrâneas. 
Figura 2 - Influências da dinâmica do uso da terra e interferências artificiais na interação água-solo-

vegetação-atmosfera.

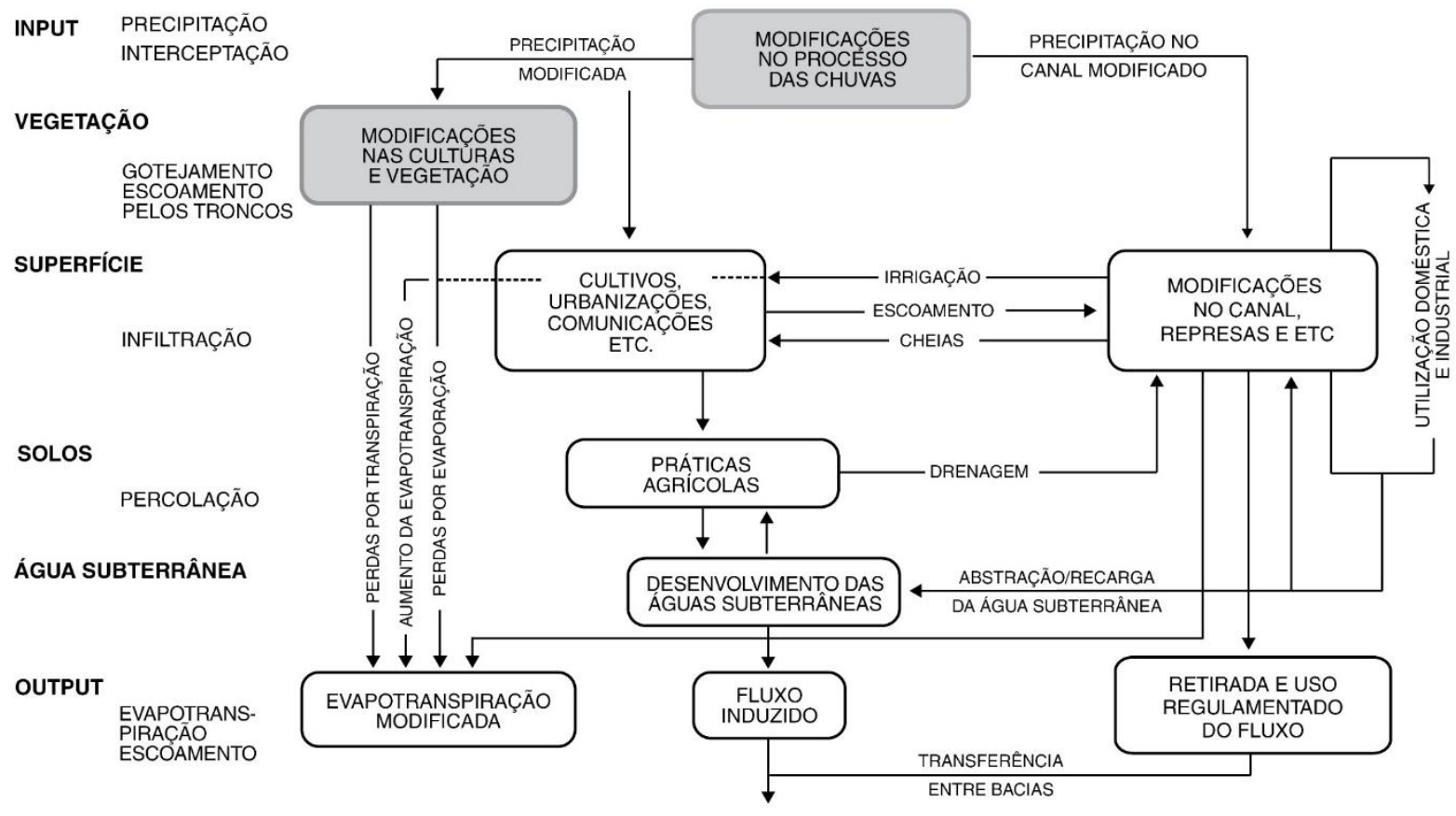

Fonte: Christofoletis (1999).

\subsection{FLUXO DE ENERGIA NO SOLO}

Outra forma de compreender a dinâmica termohidrológica, essencial para a sustentabilidade da irrigação, é através do estudo dos fluxos de energia no sistema águasolo-planta-atmosfera, onde se busca entender como a radiação solar que alcança a superfície das plantações interage e se distribui. O saldo de radiação $\left(R_{N}\right)$ é particionado nos fluxos de calor latente $(\lambda E)$, sensível $(H)$ e no interior da superfície $(G)$ (ALLEN et al., 1998). $R_{N}$ é redistribuído em $\lambda E, H$ e $G$, considerando apenas os fluxos verticais, ignorando as taxas horizontais de transferência de energia, por advecção, as quais podem ser significantes nas interfaces de culturas irrigadas e vegetação natural. Outros termos, tais como calor armazenado ou liberado das copas, ou a energia utilizada em processos metabólicos, não são considerados, por serem pequenas frações da energia disponível na escala temporal diária (TEIXEIRA et al., 2015b, 2017b). Valores de $R_{N}$ positivos significam fluxos para a superfície, enquanto os positivos para $\lambda E, H$ e $G$ são provenientes da superfície. A equação do balanço de energia está descrita na Equação 2: 


$$
R_{N}=\lambda E+H+G
$$

onde $R_{N}$ é o saldo de radiação, $\lambda E$ é o fluxo de calor latente, $H$ é o fluxo de calor sensível e $G$ é o fluxo de calor no solo. Todos os termos da Equação 2 podem ser expressos em $\mathrm{W} \mathrm{m}^{-2}$ ou $\mathrm{MJ} \mathrm{m}^{-2} \mathrm{~d}^{-1}$, sendo valores positivos ou negativos. A Figura 2 exibe um esquema com a direção dos fluxos descritos na Equação 2.

Em condições de campo $R_{N}$ pode ser medido com pirgeômetros e piranômetros ou com saldo radiômetros acima da superfície vegetada. Os componentes $\lambda E$ e $H$ podem ser medidos diretamente (sistema das correlações turbulentas) ou obtidos indiretamente dos gradientes de temperatura e umidade (sistema da razão de Bowen). Geralmente, em experimentos de campo, $G$ é medido com fluxímetros enterrados na superfície do solo ou através de termopares em diferentes profundidades. O fluxo de calor no solo $(G)$ consiste na quantidade de energia utilizada para seu aquecimento, sendo geralmente modelado como uma troca de calor por condução. A atmosfera também se aquece quando $R_{N}$ é positivo. Este aquecimento ocorre a partir da superfície, então a temperatura da superfície $\left(T_{S}\right)$ durante as horas do dia, excede a temperatura do ar $\left(T_{A}\right)$. O componente do balanço de energia $H\left(\mathrm{MJ} \mathrm{m}^{-2} \mathrm{dia}^{-1}\right)$ é essa taxa de transferência de calor entre a superfície e $\mathrm{o}$ ar por convecção e condução, devido a uma diferença de temperatura. A troca de calor sensível é determinado pelo estado da camada limite da atmosfera e pelas propriedades da superfície (TEIXEIRA, 2008). 
Figura 3 - Balanço de energia no solo de acordo com os fluxos de calor latente $(\lambda E)$, sensível $(H)$ e calor no solo $(G)$ como partições do saldo de radiação $\left(R_{N}\right)$ originada da radiação solar global $\left(R_{G}\right)$

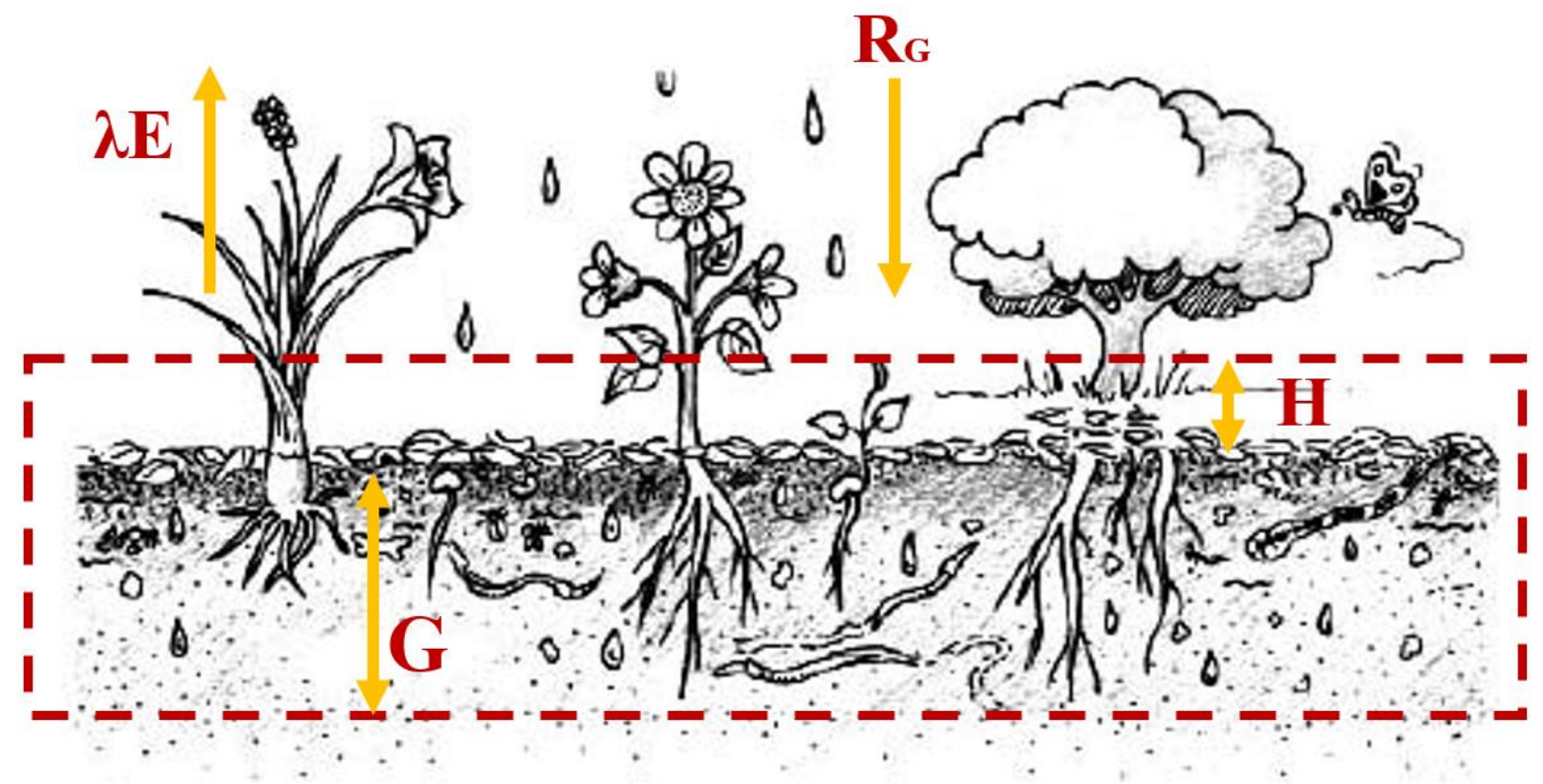

Fonte: Silva et al. (2019a).

O fluxo de calor latente ocorre quando há uma diferença na concentração de vapor de água entre a superfície vegetada e a atmosfera, consistindo na energia envolvida na evaporação da água da superfície e na transpiração vegetal. Esse fluxo, em termos de coluna de água, é a evapotranspiração.

\subsection{AS QUATRO PRINCIPAIS VARIANTES DO CONCEITO DE EVAPOTRANSPIRAÇÃO}

Thornthwaite (1948) introduziu o conceito de evapotranspiração potencial para obter um elemento meteorológico que representasse a necessidade de água da vegetação, em condições similares à da água fornecida pela precipitação pluvial, e quantificar racionalmente o fator umidade, no clima.

Pela dificuldade empírica na sua obtenção, o conceito de evapotranspiração potencial está em desuso, sendo mais utilizada a de evapotranspiração de referência. Vale ressaltar que artigos científicos e trabalhos publicados em congressos muitas vezes confundem a evapotranspiração potencial com a de referência, sendo propagada erroneamente que são termos sinônimos.

A evapotranspiração de referência $\left(E T_{o}\right)$ é a evapotranspiração de uma extensa superfície vegetada com vegetação rasteira (normalmente gramado), em crescimento ativo, 
cobrindo totalmente o solo, com altura entre 8 e $15 \mathrm{~cm}$ (IAF $\approx 3$ ), sem restrição hídrica e com ampla área de bordadura para evitar a advecção de calor sensível $(\mathrm{H})$ de áreas adjacentes (ALLEN et al., 1998). Nesse caso a ET depende apenas das variáveis meteorológicas, sendo, portanto, o $E T_{o}$ uma variável meteorológica, que expressa o potencial de evapotranspiração para as condições meteorológicas vigentes.

A evapotranspiração potencial $\left(E T_{P}\right)$ é a soma das perdas de água causadas pela evaporação da superfície (na altura do solo) e pela transpiração da vegetação. A $E T_{P}$ considera que oconteúdo de água no solo esteja próximo à capacidade de campo e que a superfície está totalmente coberta, desconsiderando, assim, áreas com solo exposto (onde ocorre apenas evaporação). Em outras palavras, a $E T_{P}$ se refere ao fluxo hídrico da vegetação em áreas grandes sob condições ótimas de umidade na zona das raízes e excelentes condições de manejo e ambientais.

A evapotranspiração de cultura $\left(E T_{C}\right)$ é a evapotranspiração de uma cultura específica em dada fase de seu desenvolvimento, sem restrição hídrica, em condições ótimas de crescimento e com ampla área de bordadura para evitar a advecção de calor sensível $(\mathrm{H})$ de áreas adjacentes. Assim, a $E T_{C}$ depende das condições meteorológicas, expressas por meio da $E T_{o}$, do tipo de cultura (maior ou menor resistência à seca) e da área foliar. Como a área foliar da cultura padrão é constante e a da cultura real varia, o valor de $K_{C}$ (tabelado) também irá variar.

$$
E T_{C}=K_{C} E T_{o}
$$

Atualmente a principal referência para valores de $K_{C}$ é o manual 56 da FAO (ALLEN et al., 1998). Os valores de $K_{C}$ acompanham as fases fenológicas das culturas. Essa classe de ET costuma ser considerada sinônimo de $E T_{P}$, no presente trabalho consideramos que a $E T_{C}$ está associada ao $K_{C}$, enquanto a $E T_{P}$ pode abarcar outros métodos de classificação (SILVA, 2019).

A evapotranspiração real $\left(E T_{A}\right)$ é a perda de água por evaporação e transpiração em qualquer das condições reinantes (atmosféricas e de umidade do solo), sendo necessário medições in-situ com lisímetros. O processo físico no qual ocorre o fluxo hídrico das superfícies evaporativas para a atmosfera se refere a $E T_{A}$. Este fluxo ocorre através das folhas das plantas pelos estômatos como transpiração real $(T)$ e diretamente da superfície do solo como evaporação real $(E)$. Os estômatos são pequenas aberturas por onde os gases e o vapor d'água passam. $\mathrm{A} E T_{A}$ envolve todas as condições da superfície vegetada. Devido às condições nem sempre ótimas de manejos culturais, e restrições ambientais que 
afetam o desenvolvimento das culturas e limitam os fluxos hídricos, a $E T_{A}$ é geralmente menor que a $E T_{C}$ e $E T_{P}$.

Valores da evapotranspiração real $\left(E T_{A}\right)$ podem desviar daqueles das condições potenciais $\left(E T_{P}\right)$, devido a ocorrência de pragas e doenças, salinidade do solo, baixa fertilidade, escassez e excesso hídricos. Os desvios das condições ótimas afetam a produtividade e a qualidade dos produtos colhidos. Em cultivos irrigados o processo predominante é a transpiração vegetal, enquanto em áreas com pouca cobertura foliar predomina a evaporação do solo.

Os modelos de estimativa de evapotranspiração por sensoriamento remoto focam na evapotranspiração real $\left(E T_{A}\right)$, por ela ser mais relacionada com a cobertura do solo do que as demais, que são voltadas para superfícies de referência pontuais $\left(E T_{O}\right.$ e $\left.E T_{P}\right)$ e tabelamentos para manejo de irrigação $\left(E T_{C}\right)$. Também as bases de dados já disponíveis (no GEE) enfocam a $E T_{A}$.

\section{FUNDAMENTAÇÃO TECNOLÓGICA: SENSORIAMENTO REMOTO}

\subsection{SENSORES E SATÉLITES}

O sensoriamento remoto fornece medições não destrutivas, automáticas e periódicas. A maioria desses métodos pode ser calibrada e validada com dados medidos em campo, permitindo avaliar a capacidade do sensor, dentro de sua resolução espacial e temporal, de modelar a evapotranspiração a nível de propriedade, bacia ou região. Essas características conferem um grande potencial tanto para monitorar o estresse hídrico quanto para programar a irrigação e avaliar o desenvolvimento fenológico das culturas irrigadas e de sequeiro.

Sensores remotos são capazes de identificar assinaturas espectrais de todas as superfícies e objetos. Os sensores podem detectar alvos com uma resolução espacial definida pela menor área espacial possível de ser amostrada ou visualizada, sendo essa a resolução espacial de cada pixel caracterizada por dados espaciais e espectrais específicos (SHIA e WANGA, 2014) como a intensidade da refletância ou da emitância medida por um sensor (JAWAK, DEVLIYAL e LUIS, 2015). Sensores necessitam de um suporte, no caso do presente estudo, abordamos os sensores embarcados em satélites orbitais, mas há 
sensores embarcados em veículos aéreos tripulados ou não-tripulados, ou simplesmente, sensores manuais.

Os sensores podem ser divididos pelos tipos básicos de sistemas de sensores, como ativo e passivo, sendo o último o mais comum para sensoriamento remoto da vegetação. A principal limitação dos sensores passivos é a forte relação entre aquisição de dados e iluminação (hora do dia e ano; latitude) e condições climáticas (cobertura de nuvens), pois requerem medições precisas da radiação solar e correção dos efeitos atmosféricos (SHAW e BURKE, 2003; SHIA e WANGA, 2014; JAWAK, DEVLIYAL e LUIS, 2015). Sensores ativos utilizam uma fonte artificial de energia; no sensoriamento remoto ativo, podendo-se controlar a natureza (comprimento de onda, potência, duração) da energia da fonte. Sensores ativos (sistemas de radar, LiDAR) não precisam de luz solar e condições climáticas perfeitas (gerando menor dependência aos fatores ambientais); portanto, eles podem ser empregados para os objetivos de sensoriamento remoto mesmo à noite ou sob condições adversas (neblina, nuvens, chuva etc.). No presente trabalho abordamos apenas sensores remotos passivos.

Os instrumentos de sensoriamento remoto são projetados para identificar vários comprimentos de onda do espectro eletromagnético, conhecidos como "bandas". Cada instrumento é caracterizado por um número específico de bandas e larguras de comprimentos de onda detectados; alguns instrumentos detectam bandas discretas e específicas, enquanto outros detectam comprimentos de onda bastante estreitos ou bandas mais amplas (como comprimentos de onda multiespectrais, visíveis e de infravermelho próximo, micro-ondas, sistemas de detecção termal) (SHAW e BURKE, 2003).

A interação radiação solar-vegetação acontece na região foliar durante o processo de fotossíntese e tem relação direta com as detecções remotas que resultam em imagens de satélite. Dentro da região visível do espectro eletromagnético (no intervalo entre 0,4 e 0,7 $\mu \mathrm{m}$ ) ocorre absorção da radiação incidente nas faixas do azul (com comprimento de onda central de 0,4 $\mu \mathrm{m})$ e vermelho $(0,7 \mu \mathrm{m})$, enquanto na região do verde $(0,55 \mu \mathrm{m})$ ocorre maior reflexão. $\mathrm{Na}$ faixa espectral do infravermelho próximo (acima de 0,7 $\mu \mathrm{m}$ ), a reflectância é ainda maior que a do verde (JENSEN, 2000; FIORIO et al., 2018). Esse comportamento espectral é um padrão que flutua quantitativamente de acordo com outros fatores temporais, como o estádio de desenvolvimento da cultura, umidade do solo, irrigação e outros parâmetros agroclimáticos (PONZONI, SHIMABUKURO, 2010, FORMAGGIO, SANCHES, 2017, FIORIO et al., 2018). 
Também é necessário considerar o comportamento espectral dos solos, já que há locais de solo exposto e estradas junto às lavouras (FORMAGGIO, SANCHES, 2017). Os principais fatores envolvidos na reflectância dos solos são os teores de óxidos de ferro e de matéria orgânica, a textura, a umidade e a rugosidade (MENESES et al., 2019). Assim como nas folhas, a umidade do solo interfere na refletância, fazendo com que ela seja menor, principalmente na região do infravermelho médio (SHIA, WANGA, 2014). Por isso vale destacar que solos com textura fina possuem maior capacidade de retenção de água, logo, apresentem menor reflectância que solos com textura mais grosseira, pois tendem a reter menos água (FORMAGGIO, SANCHES, 2017). Nesse sentido, é importante, sempre que possível, unir conhecimento in-situ da área de estudo aos dados obtidos por sensoriamento remoto para que a interpretação seja convergente à realidade.

No contexto dos sensores passivos, embarcados em satélites orbitais, as opções públicas mais difundidas tem sido os sensores embarcados nos satélites Sentinel-2, Landsat-8 e Aqua/Terra.

Tabela 2 - Características das bandas sensores Sentinel-2, Landsat-8 e MODIS, aplicáveis a estudos agroambientais, e suas respectivas faixas de comprimento de onda, de imageamento e resolução espacial e temporal.

\begin{tabular}{|c|c|c|c|c|}
\hline Sensor & $\begin{array}{l}\text { Resolução } \\
\text { Espacial }\end{array}$ & $\begin{array}{c}\text { Bandas } \\
\text { Espectrais }\left(B_{N}\right) \\
(\mu \mathrm{m})\end{array}$ & $\begin{array}{c}\text { Faixa de } \\
\text { Imageamento }\end{array}$ & $\begin{array}{c}\text { Resolução } \\
\text { Temporal }\end{array}$ \\
\hline Sentinel-2/MSI & $10 \mathrm{~m}$ & $\begin{array}{c}\text { B2: } 0,46-0,52 \\
\text { B3: } 0,53-0,59 \\
\text { B4: } 0,63-0,69 \\
\text { B8: } 0,797-0,887\end{array}$ & $290 \mathrm{~km}$ & 5 dias \\
\hline Landsat-8 & $\begin{array}{l}\text { OLI: } 30 \mathrm{~m} \\
\text { TIRS: } 100 \mathrm{~m}\end{array}$ & $\begin{array}{c}\text { B1: } 0,43-0,45 \\
\text { B2: } 0,45-0,51 \\
\text { B3: } 0,53-0,59 \\
\text { B4: } 0,64-0,69 \\
\text { B5: } 0,85-0,88 \\
\text { B6: } 1,570-1,650 \\
\text { B7: } 2,11-2,29 \\
\text { B10: } 10,6-11,19 \\
\text { B11: } 11,5-12,5\end{array}$ & $185 \mathrm{Km}$ & 16 dias \\
\hline Aqua/Terra & MODIS: 250 m & $\begin{array}{l}\text { B1: 0,62-0,67 } \\
\text { B2: 0,84-0,87 }\end{array}$ & $2330 \mathrm{~km}$ & 1 a 2 dias \\
\hline
\end{tabular}


Existem outros satélites (RapidEye, Planet, QuickBird, por exemplo) com resoluções espaçotemporais mais altas, porém, suas imagens pagas, e também satélites com resolução espaçotemporal mais baixas e menos difundidas em modelagem de evapotranspiração (CBERS, Amazônia-1, por exemplo). A Tabela 2 apresenta as principais bandas dos satélites Sentinel-2, Landsat-8 e Aqua/Terra.que tem potencial de aplicação em estudos agroambientais. O produto MODIS tem resolução espacial menor que as dos satélites CBERS e Amazônia-1, entretanto, é largamente aplicada em estudos regionais por sua alta resolução temporal.

Os sensores MODIS, Landsat-8/OLI e Sentinel-2/MSI tem suas características e aplicações exploradas nas próximas seções.

\subsection{MISSÃO LANDSAT}

O sensor Landsat-8/OLI-TIRS (NASA, 2019b), lançado no dia 11 de fevereiro de 2013, é proveniente de uma parceria entre o USGS (United States Geological Survey) e a NASA (National Aeronautics and Space Administration) (USGS, 2013). O satélite possui dois sensores: OLI (Operational Land Imager), com nove bandas, e TIRS (Thermal Infrared Sensor), com duas bandas (USGS, 2013). Os satélites LANDSAT fornecem dados e informações muito importantes, e que podem ser utilizadas nas tomadas de decisões em estudos ambientais. A Tabela 3 apresenta as características das imagens do sensor OLI do satélite LANDSAT-8.

Tabela 3 - Aplicações agroambientais das bandas espectrais do Landsat-8/OLI com resolução espacial de 30 metros.

\begin{tabular}{c|c}
\hline $\begin{array}{c}\text { Bandas } \\
\text { Espectrais }(\mu \mathrm{m})\end{array}$ & Aplicações \\
\hline B2: 0,45-0,51 & Sensibilidade a queimadas (SILVA, PESTANA, MARTINS, 2019). \\
\hline B3: 0,53-0,59 & $\begin{array}{r}\text { É sensível à presença de sedimentos em suspensão, possibilitando sua } \\
\text { análise em termo quali-quantitativos (PEIXOTO et al., 2018). }\end{array}$ \\
\hline B4: 0,64-0,67 & $\begin{array}{c}\text { Boa diferenciação de tipo de vegetação (SHIMABUKURO e SMITH, 1991). } \\
\text { Mapeamento de mata-galeria e entalhe dos cursos dos rios em regióes com } \\
\text { pouca vegetação (SILVA JUNIOR et al., 2021). Permite identificação de áreas } \\
\text { agrícolas (SILVA et al., 2019d). }\end{array}$ \\
\hline B8: 0,85-0,88 & $\begin{array}{c}\text { Identificação e delineamento de corpos d'água. Sensibilidade à rugosidade de } \\
\text { dossel florestal e de terreno (POLLO et al., 2019). Permite identificação de } \\
\text { macrófitas aquáticas e de áreas agrícolas (MINHONI et al., 2015). }\end{array}$ \\
\hline
\end{tabular}


O Landsat-8/OLI apresenta alta resolução espacial (comparado ao MODIS) e possibilita análises a nível de propriedade rural, principalmente quando ocupada por talhões com dimensões laterais maiores que 30 metros.

\subsection{MISSÃO SENTINEL}

Os satélites Sentinel 1 até 5 foram projetados especificamente para monitoramento ambiental (VAN DER WERFF, VAN DER MEER, 2015) e lançados em 2015. Este sistema possui bandas com resolução espacial de $10 \mathrm{~m}$ (bandas do visível e infravermelho próximo), 20 m (infravermelho) e 60 m (demais bandas), com campo de visão de 290 km, capacidade de revisita de 5 dias (dois satélites) e um conjunto de bandas moderadamente grandes (13 bandas espectrais) com o objetivo de fornecer cobertura global da terra.

A missão apresenta dados que funcionam como uma continuidade das missões anteriores (Landsat e SPOT) e fornece variáveis geoquímicas e físicas, mapas de cobertura da terra e mapas de detecção de mudança de terra. A Figura 3 compara as bandas do Sentinel-2 com as do Landsat-7 e 8, mostrando que foram definidas em intervalos similares, o que permite que análises sejam feitas com ambos os satélites com um grau de incerteza aceitável (SILVA et al., 2019b).

Figura 4 - Comparação entre os intervalos de faixa do espectro eletromagnético das bandas dos sensores das missões Sentinel e Landsat.

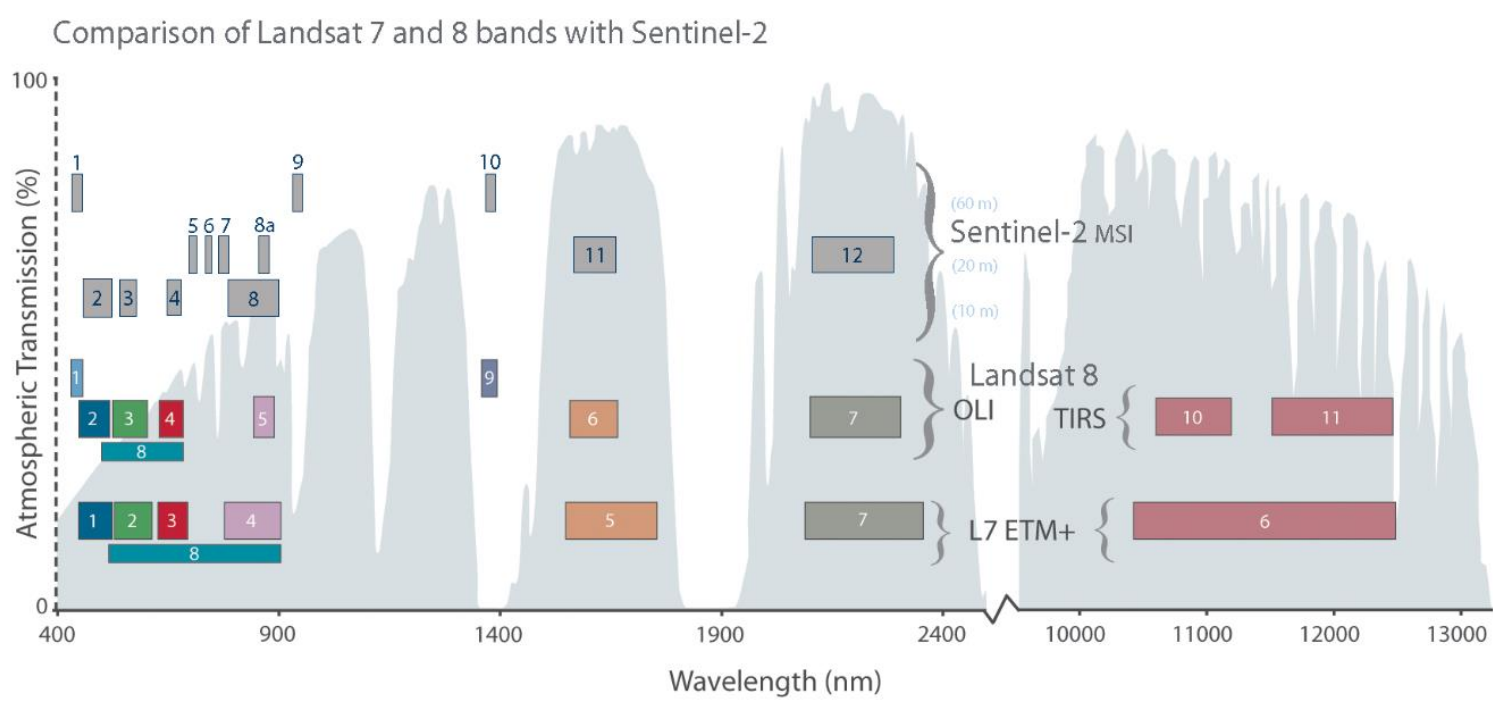

Fonte: https://eros.usgs.gov/sentinel-2) 
Assim propriedades rurais podem ser analisadas remotamente e talhões com dimensões laterais maiores que 10 metros podem ser detalhados mediante modelos espaciais com a utilização de imagens Sentinel-2.

\subsection{PRODUTOS MODIS}

O sensor MODIS está a bordo das plataformas Terra e Aqua, lançados pela National Aeronautics and Space Administration (NASA, 2019a) em 18 de dezembro de 1999 e 4 de maio de 2002, respectivamente, e apresenta alta resolução espectral, com 36 bandas, e temporal, com obtenção de dados diários. Possui resoluções espaciais de 250 metros nas bandas do vermelho (B1) e do infravermelho próximo (B2) e de 500 metros nas demais bandas do visível e do infravermelho próximo. Este sensor foi concebido para fins de monitoramento ambiental em três diferentes campos de estudo: atmosfera, oceano e terra. A Tabela 4 apresenta potenciais aplicações para bandas espectrais do MODIS com resolução espacial de $250 \mathrm{~m}$.

Tabela 4 - Aplicações agroambientais das bandas espectrais do MODIS com resolução espacial de 250 metros.

\begin{tabular}{c|c}
$\begin{array}{c}\text { Bandas } \\
\text { Espectrais }(\mu \mathrm{m})\end{array}$ & Aplicações \\
\hline B1: $0,62-0,67$ & Identificação de áreas vegetadas florestais e agrícolas (SILVA et al., 2018b) \\
\hline B2: $0,84-0,87$ & $\begin{array}{c}\text { Identificação e delineamento de grandes lagos, lagoas e pântanos (TEIXEIRA } \\
\text { et al., 2015a) }\end{array}$ \\
\hline
\end{tabular}

Sua moderada resolução espacial é mais adequada a estudos em escala regional, a nível de bacia hidrográfica, e tem a vantagem de ter um tempo de revisita de 1 a 2 dias.

\section{SENSORIAMENTO REMOTO DA EVAPOTRANSPIRAÇÃO E FLUXOS DE ENERGIA}

As opções de sensores, embarcados em satélites orbitais e disponibilizadas publicamente, apresentadas anteriormente têm sido utilizadas para embasar estimativas de $E T_{A}$ e fluxos de energia no solo. Também há modelagens de estimativas que incorporam outras fontes de dados de sensoriamento remoto e são disponibilizadas prontas. A seguir apresentamos os modelos de estimativa de evapotranspiração baseadas nos sensores remotos passivos mais difundidas (porém, que precisam ser processadas pelo pesquisador 
em algum software) e também as bases de dados com a estimativa de $E T_{A}$ previamente modelada (que apresentaremos em um painel interativo do GEE).

\subsection{MODELAGEM ESPAÇO-TEMPORAL DA EVAPOTRANSPIRAÇÃO REAL E FLUXOS DE ENERGIA BASEADA EM IMAGENS DE SATÉLITE}

Em geral, modelos de estimativa de evapotranspiração por meio de sensoriamento remoto envolvem equações empíricas, de balanço de energia e/ou índices de vegetação. Equações empíricas são geradas do cruzamento de dados radiométricos com medições em campo (por exemplo, por meio de análise de regressão linear). É necessário realizar validações que comprovem a representatividade dessas equações, por exemplo, avaliando a sua precisão em diferentes microclimas e regiões, para restringir seu uso para ambientes em que sejam preditores suficientemente eficientes.

Os modelos mais antigos e difundidos são o Surface Energy Balance Algorithm for Land - SEBAL (BASTIAANSSEN et al., 1998a, 1998b) e Mapping Evapotranspiration at High Resolution with Internalized Calibration - METRIC (ALLEN et al., 2007b), que se baseiam no uso das bandas do espectro visível, infravermelho próximo e infravermelho termal para obtenção da evapotranspiração como um resíduo do balanço de energia na superfície (ALLEN et. al., 2007a, 2007b). Já os modelos Operational Simplified Surface Energy Balance (SSEBop) (SENAY et al., 2013) e o Simple Algorithm for Evapotranspiration Retrieving (SAFER) (TEIXEIRA, 2010) são baseados em equações empíricas e por isso são operacionalmente mais simples. Outra importante vantagem do SSEBop e SAFER é o fato de não requererem a identificação de um conjunto de "pixels quentes" (um dos dados de entrada para os modelos SEBAL e METRIC), o que pode ser um fator limitante durante o período chuvoso de uma região (TEIXEIRA, 2010).

\subsubsection{Surface energy balance algorithms from the land (SEBAL)}

Bastiaansen et al. (1998a, 1998b) formularam e validaram, respectivamente, um modelo, baseado no balanço de energia computado por meio de sensoriamento remoto, da evapotranspiração a partir da quantificação do fluxo de calor latente obtida do resíduo da equação do balanço de energia (utilizando imagens digitais de qualquer sensor orbital que meça radiância no visível, infravermelho próximo e termal). 
Uma das hipóteses que dão base ao SEBAL é a de que a diferença de temperatura entre a temperatura aerodinâmica e do ar está linearmente correlacionada com a temperatura superficial. Essa relação é determinada usando dois pontos "âncora" onde um valor para o calor sensível é estimado baseado em um conhecimento prévio dos fluxos sobre solo exposto e seco ("pixel quente") e solo úmido ("pixel frio") (BASTIAANSEN et al., 1998a). Com isso, uma aplicação bem-sucedida do SEBAL requer uma área que seja grande o suficiente para abranger essas condições extremas, que caracterizam os pixels "âncora", e que também apresente usos da terra com transição razoavelmente homogênea, para que a hipótese de linearidade do SEBAL seja válida. Além disso, a seleção visual de pixels "quentes" e "frios" no SEBAL é associada a subjetividade do pesquisador, resultando em maiores incertezas nas estimativas do modelo.

\subsubsection{Mapping evapotranspiration with high resolution and internalized calibration (METRIC)}

O Mapping Evapotranspiration at High Resolution and With Internalized Calibration (METRIC) (ALLEN et al., 2005) foi desenvolvido para estimar o balanço de energia e evapotranspiração de maneira muito similar ao SEBAL, diferindo no equacionamento da estimativa da evapotranspiração diária, na escolha do pixel úmido e na diferença de temperatura desse pixel, sendo mais eficiente que o SEBAL em superfícies montanhosas e heterogêneas, que envolvem a utilização de modelos numéricos de terreno e dados horários de evapotranspiração (HONG et al., 2008).

A estimativa de evapotranspiração pelo METRIC foi implementada no GEE e chamase Earth Engine Evapotranspiration Flux (EEFLUX) (ALLEN et al., 2015). Esta implementação fornece vários produtos de satélite, entre eles, a $E T_{A}$. A evapotranspiração do EEFLUX é processada para qualquer imagem Landsat-7 ou Landsat-8, de 1984 até hoje. A Figura 5 apresenta uma captura de tela do website do EEFLUX. Filgueiras et al. (2019) compararam valores de $E T_{A}$ do EEFLUX com resultados do SEBAL no Brasil e encontrou aderência de $80 \%$ entre os dos modelos. 
Figura 5 - Captura de tela da página de extração de dados do EEFLUX.

$\leftarrow \rightarrow \mathrm{C} \backsim \mathrm{h}$ ttps://eeflux-level1.appspot.com

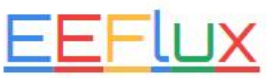

This is version 0.20 .4 of EEFlux. Automated calibration of ETrF is still evolving. The last update was June 17,2021 . See the FAQ regarding the version numbers.

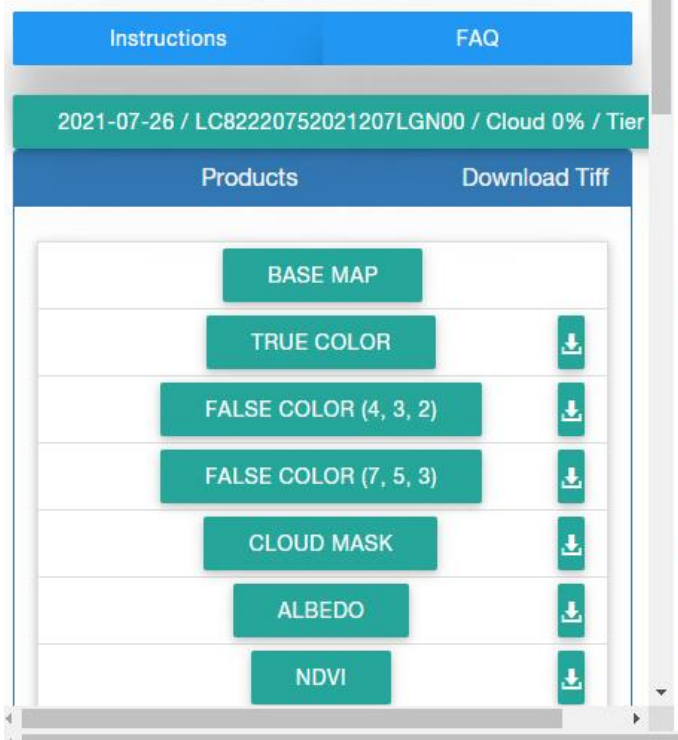

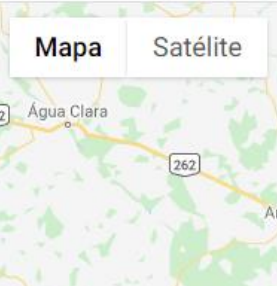

Santa Santa Rita
do Pardo
?ardo

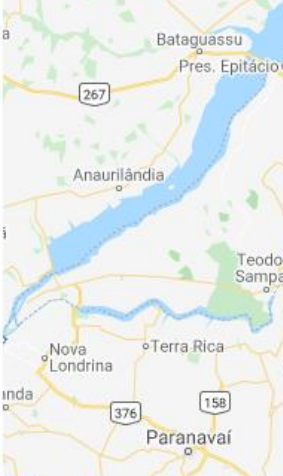

Google
Fernandópolis [154] Votuporanga Votuporanga (456) 158 3
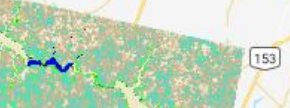

Fonte: https://eeflux-level1.appspot.com/

A principal diferença entre o SEBAL e o METRIC é o cálculo do fluxo de calor sensível. Apesar de ambos calcularem $\mathrm{H}$ a partir de um processo de autocalibração, com base em uma função aerodinâmica. No SEBAL, originalmente, a diferença de temperatura entre dois níveis está em função dos valores de $\mathrm{H}$ derivados das condições registradas no pixel quente (onde assume-se que está o máximo fluxo de calor sensível e o mínimo fluxo de calor latente) e pixel frio (onde assume-se que está o mínimo fluxo de calor sensível e o máximo fluxo de calor latente) (BASTIAANSEN et al., 1998a). Enquanto no METRIC, calcula-se a diferença de temperatura em função da evapotranspiração de referência para alfafa obtida pelo método de Penman-Monteith (ALLEN et al., 2005). Em ambos os modelos, a correção da estabilidade atmosférica é realizada por meio de um processo interativo baseado na teoria da similaridade de Monin-Obukhov (ALLEN et. al., 2007b).

A quantidade de dados que os modelos SEBAL e METRIC demandam limitam sua aplicação para regiões com carência de dados. Por exemplo, para o SEBAL requer medições de velocidade do vento e uma calibração iterativa relativamente intensa. Já o METRIC, que utiliza a evapotranspiração de referência para a autocalibração, requer dados 
precisos de radiação solar, temperatura do ar, umidade e velocidade do vento, preferencialmente em uma base horária (ALLEN et al., 2007a).

\subsubsection{Simple algorithm for evapotranspiration retrieving (SAFER)}

O SAFER é um modelo elaborado por Teixeira (2010). Envolve apenas o albedo da superfície, a temperatura da superfície e o Índice de Vegetação da Diferença Normalizada (NDVI), como parâmetros obtidos por meio da associação de dados de sensoriamento remoto com dados climáticos provenientes de estações agrometeorológicas, podendo ser aplicado em áreas com variados usos da terra. Apesar deste algoritmo ter sido inicialmente aplicado e validado nas condições semiáridas do Nordeste brasileiro, o uso das equações originais foi aplicado e validado envolvendo outros agroecossistemas, fortemente contrastantes e sob diferentes condições termohidrológicas ao longo de vários anos.

Inicialmente denominada PM2 (TEIXEIRA, 2010), o SAFER foi aplicada em diversos agroecossistemas no Sudeste do Brasil (HERNANDEZ et al., 2014; COAGUILA et al., 2017; SILVA et al., 2018a, 2018b; SANTOS et al., 2020). Hernandez et al. (2014) aplicaram o SAFER a imagens Landsat-5 no Noroeste de São Paulo e compararam seus resultados aos do modelo SEBAL, e da metodologia do coeficiente de cultura - $K_{C}$ (ALLEN et al., 1998) da Food Agriculture Organization (FAO), nas culturas de milho, feijão e cana-de-açúcar, irrigadas por pivôs centrais. A evapotranspiração por ambos os algoritmos foi mais elevada que a estimada pelo método da FAO, sendo as superestimavas relacionadas aos erros nas considerações dos estágios fenológicos, ao aplicar os valores de $K_{C}$ tabelados. Entretanto, verificou-se que o SAFER apresentou melhor desempenho que o SEBAL em condições de menor índice de área foliar. Com a versão atual do algoritmo SAFER, é possível utilizar imagens de satélite com e sem suas bandas térmicas (TEIXEIRA et al., 2014; ARAUJO et al., 2019; SILVA et al., 2019a). Silva et al. (2019c) encontraram uma tendência a valores maiores de $E T_{A}$ pelo METRIC comparado ao SAFER em uma área subtropical do Sudeste do Brasil.

A principal vantagem apresentada pelo SAFER consiste em sua simplicidade operacional (SILVA et al. 2019a). O SAFER apresenta ainda como vantagem a possibilidade de ser implementado sem a utilização da banda termal, mas com uma menor acurácia (SILVA, 2019). 


\subsubsection{Operational simplified surface energy balance (SSEBop)}

O SSEBop (SENAY et al., 2013) permite estimar a $E T_{A}$ como uma fração da evapotranspiração de referência, tendo como base o balanço de energia na superfície, porém sem requerer sua solução completa. A inovação, comparado ao SEBAL e METRIC, consiste em incluir condições de contorno preestabelecidas para cada pixel referentes às condições de fluxo de calor latente máximo (pixel frio) e mínimo (pixel quente), tornando desnecessária a escolha manual desses pixels. O pixel frio é estimado a partir da temperatura do ar e o pixel quente como um valor máximo obtido por um valor de amplitude de temperatura fixo (SENAY et al., 2013). Essa automatização permite a operacionalização do modelo em regiões mais complexas. A complexidade hidroclimática de uma área impede o uso do SEBAL e METRIC, que requerem uma região hidroclimatologicamente uniforme justamente para que as condições climáticas do conjunto de pixels quentes e frios selecionados sejam representativas.

Recentemente, a Agência Nacional de Águas (ANA) lançou um estudo inédito de estimativa de $E T_{A}$ através da automatização do modelo SSEBop com uso da API do GEE (ANA, 2020). O produto é gerado para o todo o território brasileiro, que ainda carece de dados sobre evapotranspiração, que são essenciais na gestão hídrica levando em conta a demanda de uso da água pela agricultura irrigada. A Figura 6 apresenta uma captura de tela do website do SSEBoP-BR. 
Figura 6 - Captura de tela da página de extração de dados do SSEBoP-BR.

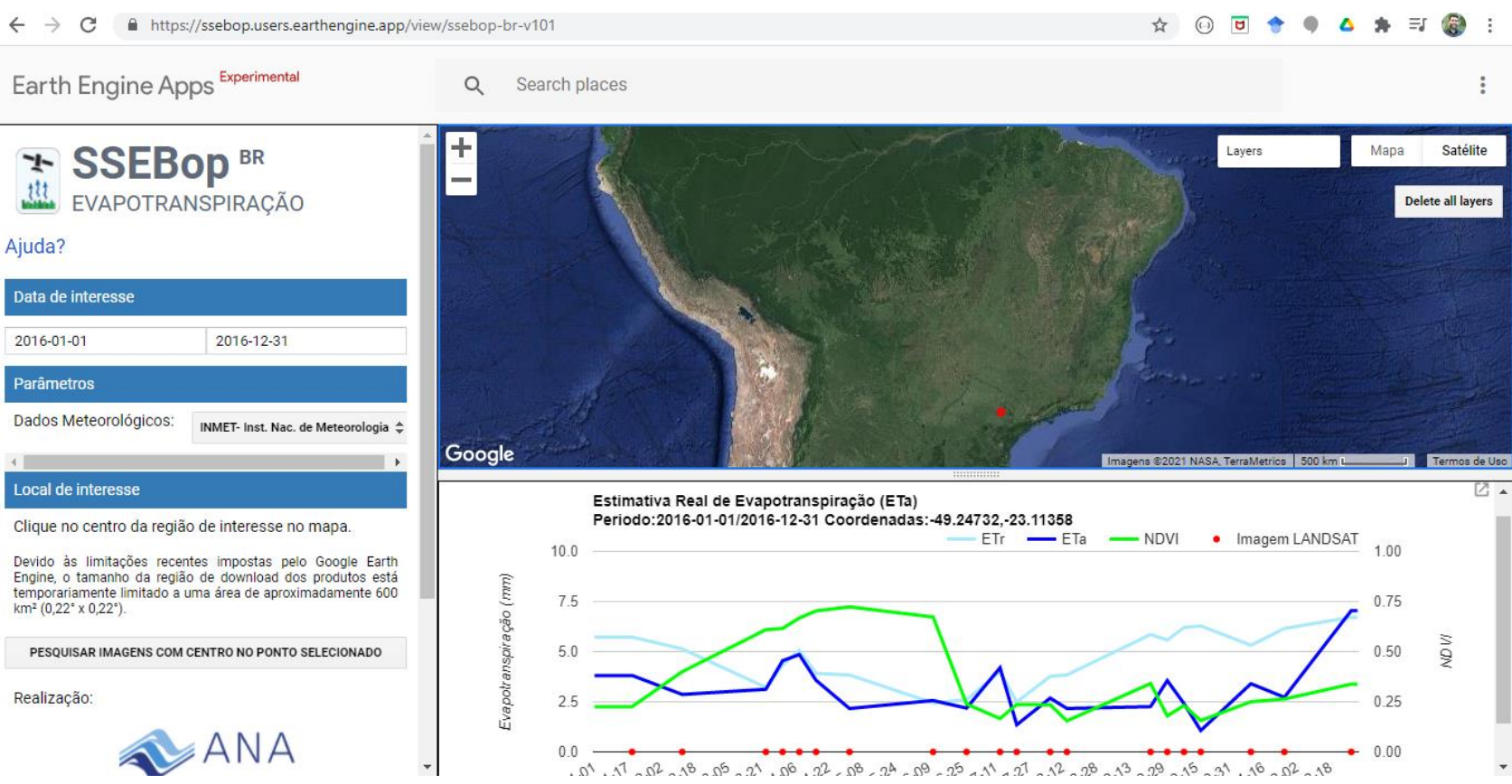

Fonte: https://ssebop.users.earthengine.app/view/ssebop-br-v101

\subsection{BASES DE DADOS DE ESTIMATIVAS DE EVAPOTRANSPIRAÇÃO REAL}

Além dos modelos que são implementados por pesquisadores para serem aplicados em imagens de satélite, há bases de dados de $E T_{A}$ já prontas que foram processadas com diferentes metodologias.

\subsubsection{Global land data assimilation system (GLDAS)}

O Global Land Data Assimilation System (GLDAS) (RODELL et al., 2004) foi desenvolvido em conjunto por cientistas da GSFC da NASA, National Oceanic and Atmospheric Administration (NOAA) e National Centers for Environmental Prediction (NCEP). Tem como objetivo processar produtos de dados observacionais baseados em satélite e no solo, usando técnicas de modelagem da superfície terrestre e de assimilação de dados, para gerar campos de estados e fluxos da superfície terrestre (BEAUDOING; RODELL; NASA/GSFC/HSL, 2020). O software, que foi simplificado e paralelizado pelo projeto irmão LIS (Land Information System), dirige vários modelos de superfície terrestre e integra uma enorme quantidade de dados baseados em observação, que são executados globalmente em altas resoluções e capazes de produzir resultados em tempo quase real (RODELL, 2020). O GLDAS tem parâmetros de solo baseados em conjuntos de dados 
globais de alta resolução espacial de Reynolds, Jackson e Rawls (2000), um conjunto de dados que inclui informação sobre frações de areia, silte e argila e porosidade, entre outros campos, e é baseado no mapa mundial de solo da FAO, vinculado a um banco de dados global de mais de 1300 núcleos de amostra de solo. Dados de elevação são definidos pelo GTOPO30 (VERDIN; GREENLEE, 1996), com os campos de forçantes meteorológicas (temperatura, pressão, umidade e radiação de ondas longas) ajustados para diferenças na elevação do GLDAS e na respectiva altura do terreno do modelo. Parâmetros de cobertura terrestre são obtidos atualmente usando os conjuntos de dados da superfície terrestre do sensor MODIS, que monitora o uso e ocupação da terra segundo o IGPB land cover classification. Algumas análises da vegetação utilizadas no GLDAS são o Leaf Area Index (LAl) e Canopy greenness fraction ( $f g$ ).

Atualmente, técnicas de assimilação de dados para incorporar produtos hidrológicos baseados em satélite, incluindo cobertura de neve e água equivalente, umidade do solo, temperatura da superfície e índice de área foliar, estão sendo implementadas. As suas estimativas globais sobre a superfície da terra auxiliam em previsões sobre clima, estudos hidrológicos e investigações do ciclo da água. Atualmente, 20 anos de dados do GLDAS Noah L4 estão disponíveis em escala temporal de 3 horas e resolução espacial de 0,25 graus com cobertura global (BEAUDOING; RODELL; NASA/GSFC/HSL, 2020).

\subsubsection{Famine early warning systems network (FEWS NET) land data assimilation system (FLDAS)}

O Famine Early Warning Systems Network (FEWS NET) Land Data Assimilation System (FLDAS) foi desenvolvido com recursos do Applied Sciences Program Water Resources da National Aeronautics and Space Administration (NASA) em colaboração com o United States Geological Survey (USGS) Earth Resources Observation and Science (EROS), NASA Goddard Space Flight Center (GSFC), e a University of California at Santa Barbara (UCSB) - Climate Hazards Group (CHG). Inclui estimativas de vários modelos e forçantes hidroclimáticas por diferentes fontes de dados de entrada, como produtos de sensoriamento remoto, projetados para ajudar a garantir a segurança alimentar em países com dados escassos como os do continente africano (MCNALLY et al., 2019). Os dados modelados e produtos derivados, como percentis de umidade do solo e disponibilidade de água foram projetados e atualmente complementam as observações operacionais de 
chuvas, evapotranspiração e vegetação da FEWS NET, detectadas remotamente. Mais de 30 anos de saídas mensais das simulações FLDAS estão disponíveis ao público no Goddard Earth Sciences Data and Information Services Center (GES DISC) da NASA, e atualmente no GEE, e são recomendados para uso em estudos de hidroclimáticos (MCNALLY et al., 2017; MCNALLY et al., 2019).

\subsubsection{Monthly climate and climatic water balance for global terrestrial surfaces (TERRACLIMATE)}

O TERRACLIMATE é um conjunto de dados do balanço mensal climático e da água para a superfícies terrestre global (ABATZOGLOU et al., 2018). Esses dados fornecem informações importantes para estudos ecológicos e hidrológicos em escala global que exigem alta resolução espacial e dados variáveis no tempo. Este modelo realiza a reanálise por meio de interpolação, combinando normais climatológicas de alta resolução espacial do conjunto de dados WorldClim (WORDCLIM, 2021), com resolução espacial mais grosseira, mas com dados variáveis no tempo do CRU TS 4.0 (HARRIS et al., 2020) e a japonesa JRA-55 (ONOGl et al., 2007; EBITA et al., 2011). Conceitualmente, o procedimento aplica interpolação de anomalias variadas no tempo do CRU TS 4.0 e JRA55 à climatologia de alta resolução espacial do WorldClim, para poder criar um conjunto de dados de alta resolução espacial que cobre um registro temporal mais amplo. As informações temporais do CRU TS 4.0 são herdadas para a maioria das superfícies terrestres globais em variáveis como temperatura, precipitação e pressão de vapor. Dados do JRA55 são usados para regiões onde os dados da CRU tiveram zero estações climáticas contribuindo (incluindo toda a Antártica e partes da África, América do Sul e ilhas dispersas).

Também são produzidos conjuntos mensais de dados do balanço hídrico superficial, usando um modelo que incorpora evapotranspiração de referência, precipitação, temperatura e capacidade de água extraível do solo pela vegetação interpolada. O modelo de balanço hídrico climático Thornthwaite-Mather modificado e dados de capacidade de armazenamento de água no solo extraíveis são usados em uma grade de 0,5 graus de Wang-Erlandsson et al. (2016). Atualmente, os dados do TERRACLIMATE estão disponíveis em escala temporal mensal e resolução espacial de aproximadamente $4 \mathrm{~km}$ com cobertura global no GEE de 1958 até o presente (ABATZOGLOU et al., 2018). 


\subsubsection{MOD16A2}

O modelo MOD16A2 foi descrito pela primeira vez por Mu et al. (2011) e aprimorado em Mu et al. (2007), utiliza a abordagem de Penman-Monteith (MONTEITH, 1965), combinando dados de sensoriamento remoto com dados meteorológicos de reanálise para calcular a transpiração das plantas e do dossel, além da evaporação do solo. Os dados de entrada MODIS necessários para o algoritmo MOD16A2 incluem produtos globais de uso do solo e cobertura terrestre (MOD12Q1), índice de área foliar (LAI), radiação fotossinteticamente ativa (PAR-MOD15A2) e albedo (MCD43B2) (WESTERHOFF, 2015). Em relação aos parâmetros meteorológicos necessários para o algoritmo MOD16A2, são utilizados dados de reanálise diária do Global Modeling and Assimilation Office Research Site (GMAO) referentes à radiação solar incidente, temperatura do ar e pressão de vapor de água, com resolução espacial de $1.00^{\circ} \times 1.2^{\circ}$ (MU et al., 2007; ELNASHAR et al., 2021 ; RAMOELO et al., 2014). O produto em questão não abrange todos os usos da terra, apenas os que possuem presença de vegetação.

\section{A ESCOLHA DO MODELO/BASE DE DADOS: ASPECTOS PRÁTICOS POR MEIO DE UM PAINEL INTERATIVO DO GOOGLE EARTH ENGINE (GEE)}

Dada a variedade e diversidade de sensores, modelos e bases de dados prontas, cabe ao pesquisador escolher a melhor opção para a aplicação a ser realizada. Para essa escolha, é necessário equilibrar questões práticas como: a) qual abordagem é mais representativa em termos espaciais e temporais? b) qual a dificuldade de manipulação envolvida em cada abordagem? c) quais as limitações computacionais do pesquisador? dentre outras possíveis questões que podem surgir nesse tipo de pesquisa (SILVA, MATULOVIC, MANZIONE, 2021).

Para utilizar adequadamente os modelos apresentados é necessário avaliar a demanda por resoluções temporal, espacial e espectral que melhor solucionem os objetivos de cada trabalho. Os sensores a bordo dos satélites Landsat, por exemplo, apresentam resolução espacial que varia de $30 \mathrm{~m}$ para as bandas multiespectrais a 60 ou $100 \mathrm{~m}$ para as bandas termais, permitindo identificar áreas irrigadas e realizar monitoramentos na escala da propriedade (SILVA, 2019). Contudo, sua resolução temporal de 16 dias, pode ser insuficiente para gestão de recursos hídricos, que exige períodos mais curtos de 
revisita. O sensor MODIS, por outro lado, apresenta resolução temporal de 2 dias e resolução espectral moderada, porém sua resolução espacial varia de 250 a 1.000 metros, sendo mais adequado para estimativas abrangendo amplas áreas (ALLEN et al., 2007a).

Dada a fundamentação teórica e tecnológica apresentada, os autores compreendem que há uma grande oportunidade, ainda pouco aproveitada, no uso de computação em nuvem para esse tipo de pesquisa (MAGNONI, SILVA, MANZIONE, 2020). A implementação de modelos de evapotranspiração com base em imagens de satélite, como as apresentadas na seção 5.1, foram largamente utilizadas nos últimos vinte anos, entretanto, podem ser operacionalmente onerosas, por necessitar de grande dispêndio de tempo e alto custo computacional desde a etapa de pré-processamento de imagens até o resultado final, e muitas inviáveis quando uma larga série temporal é requerida (SILVA et al., 2019a, 2019b, 2019d). O uso de computação em nuvem floresce como uma grande oportunidade justamente por poupar tempo nessas etapas de pré-processamento e por realizar o processamento todo na nuvem, o que também poupa custo computacional do pesquisador (MAGNONI, SILVA, MANZIONE, 2020, SILVA, 2020).

Para apresentar os aspectos práticos dessa escolha pela melhor base de dados para cada aplicação, foram desenvolvidos painéis interativos no GEE para obter séries temporais de $E T_{A}$, que podem ser calibradas com dados obtidos em campo (Figuras 7-10).

A principal vantagem de produtos disponíveis com a modelagem da $E T_{A}$ já pronta, em ambientes como o GEE, é a maior praticidade para visualizar e extrair dados espaçotemporais, já que o usuário não precisa adquirir as imagens de satélite (brutos em número digital ou refletância) e rodar os modelos localmente em seu computador, e com esse trabalho poupado pode-se aplicar tempo de projeto na calibração da modelagem disponível com dados medidos em campo e análises para melhoria da representatividade das séries temporais extraídas.

Outra oportunidade promovida pelo GEE é a criação de ferramentas que disponibilizam rápida e facilmente os dados, promovendo maior facilidade e rapidez no acesso à informação, permitindo que usuários que não são especialistas em linguagem de programação e/ou sensoriamento remoto, possam acessar esses dados de forma razoavelmente intuitiva e facilitada. Já apresentamos os casos do EEFLUX (Seção 5.1.2) e do SSEBop-BR (Seção 5.1.4) e foram desenvolvidos, no contexto do presente artigo de revisão, três painéis interativos (com seus links já disponibilizados na Seção 2.2.1). Pretendemos com essas aplicações em GEE apresentar formas mais eficientes de 
obtenção de dados, bem como auxiliar na disseminação de metodologias mais ágeis para tornar a pesquisa em monitoramento da evapotranspiração (por sensoriamento remoto) mais ágil em termos de diminuir o tempo gasto no processamento e, consequentemente, maior proximidade entre a data da aquisição do dado e a data de finalização da modelagem (MAGNONI, SILVA, MANZIONE, 2020). Vale destacar que o GEE também permite extração de imagens de satélite pré-processadas para aplicação dos modelos apresentados na Seção 5, porém não iremos tratar dessa temática no presente artigo de revisão.

Na Figura 7 é apresentado o painel P1 referente ao produto MOD16A2 Version 6 Evapotranspiration/Latent Heat Flux, com resolução temporal de 8 dias e espacial de 250m.

Figura 7 - Painel desenvolvido para visualização/extração de dados de evapotranspiração do produto MOD16A2 como descrito na Tabela 1 (Painel P1 e Código C1). Onde (1) indica o mapa de navegação, (2) um calendário no qual o usuário pode alterar a data do mosaico exibido e (3) apresenta a série temporal gerada na coordenada selecionada pelo usuário através de um clique na tela.

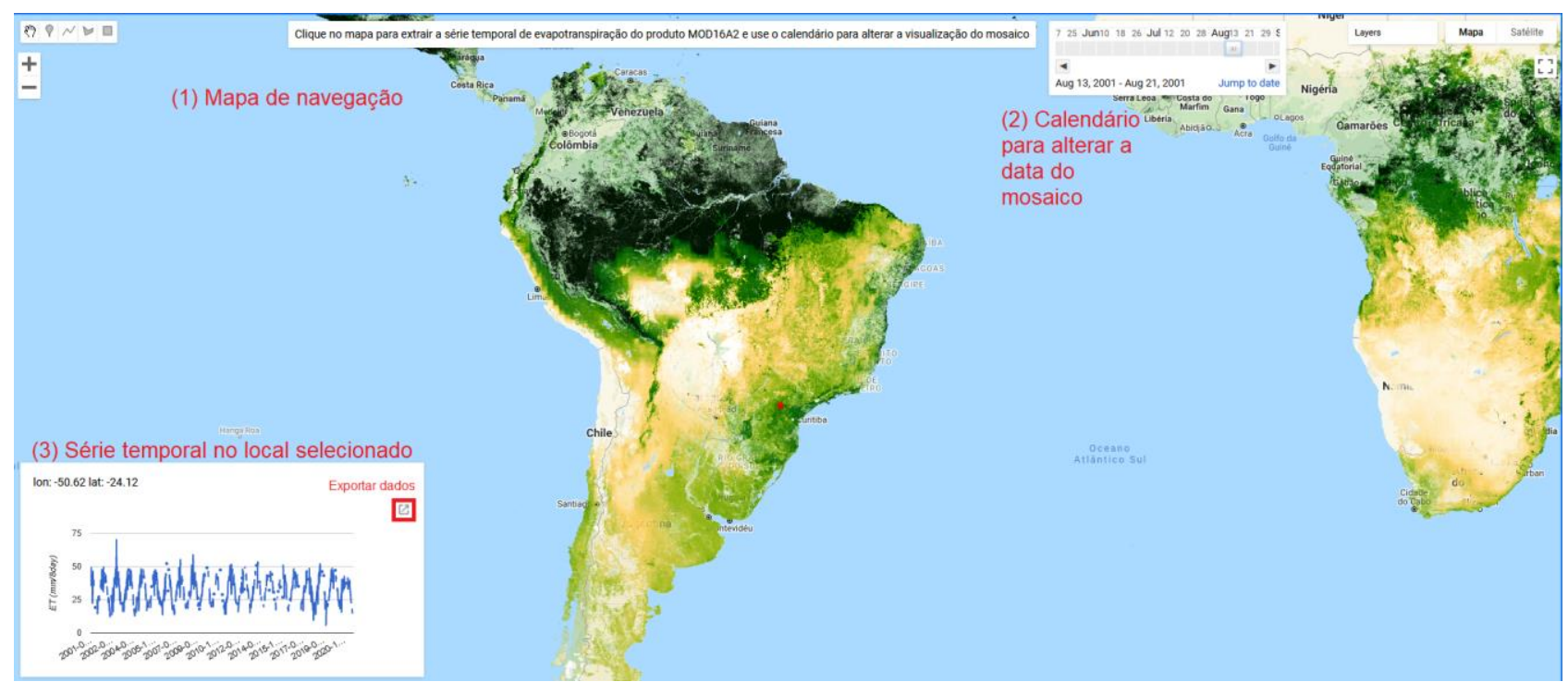

Por meio de um único clique, o usuário final pode visualizar e extrair de uma coordenada geográfica mais de 20 anos de dados de $E T_{A}$, sem a necessidade de download de arquivos matriciais ou de alocação de espaço na máquina local, a menos que realize o download da planilha com a série temporal (que tem tamanho substancialmente menor que o de arquivos matriciais) (SILVA, 2020). Já na Figura 8, o painel P2 referente ao FLDAS com resolução temporal mensal e espacial de 0,1 graus, que cobre um período de quase 40 anos (desde 1982). 
Figura 8 -Painel desenvolvido para visualização/extração de dados de evapotranspiração do produto FLDAS como descrito na Tabela 1 (Painel P2 e Código C2). Onde (1) indica o mapa de navegação, (2) um calendário no qual o usuário pode alterar a data do mosaico exibido e (3) apresenta a série temporal gerada na coordenada selecionada pelo usuário através de um clique na tela.

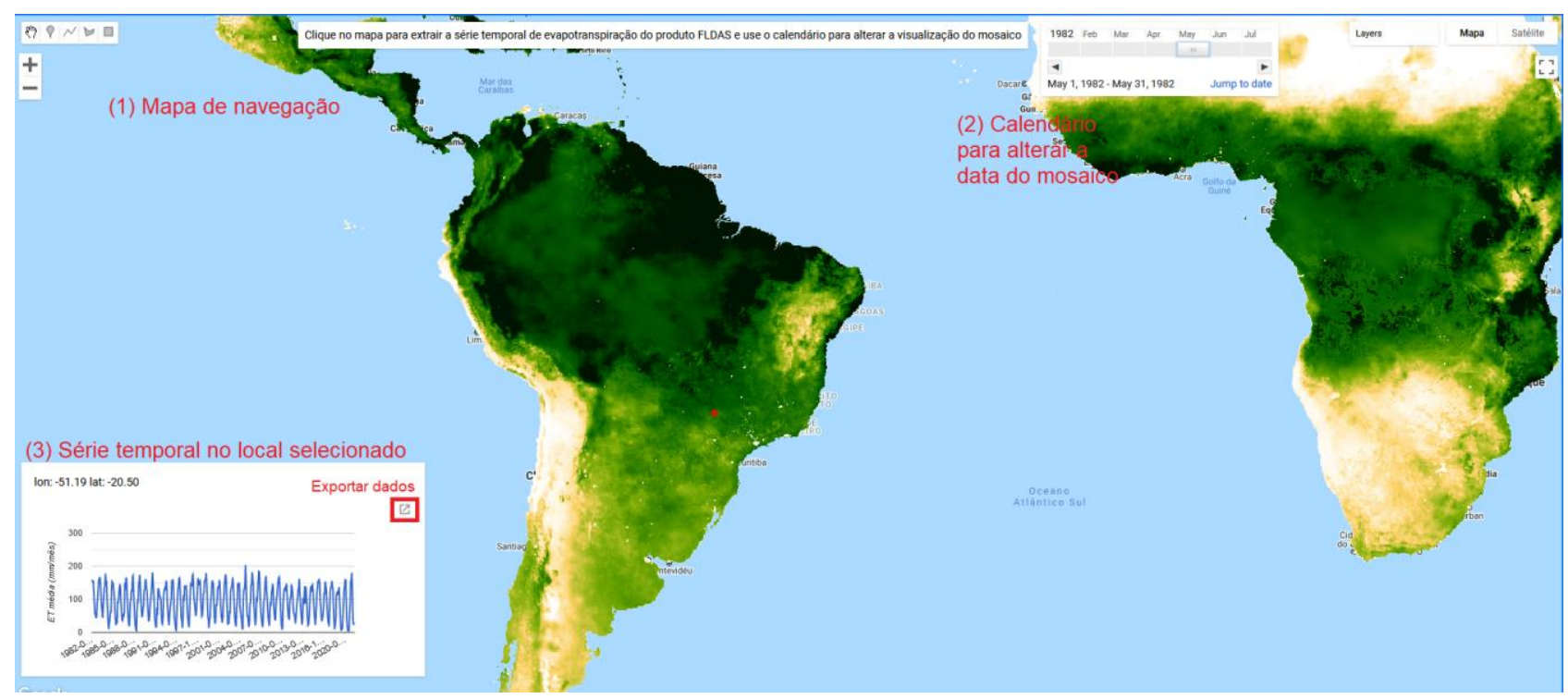

Sob uma perspectiva de visualização global, estas diferentes resoluções podem não aparentar causar diferenças nas estimativas. No entanto, quando vamos para a resolução espacial maior, mais próxima do nível do pixel, verifica-se diferenças importantes, das quais os utilizadores destes dados devem levar em consideração, por isso recomendamos a calibração desses resultados com dados medidos em campos, sempre que disponíveis. $\mathrm{Na}$ Figura 9, o painel P3 apresenta o comparativo entre o MOD16A2 e o FLDAS.

Observamos o impacto da resolução espacial e temporal nas estimativas de $E T_{A}$ ao comparar as resoluções de cada uma das bases. Observamos a maior capacidade de distinção do uso na terra nas estimativas de $E T_{A}$ pelo produto do MOD16A2, enquanto o FLDAS, por possuir uma resolução espacial inferior (pixels maiores), tem menos capacidade de distinguir os usos da terra pois, pela sua resolução espacial um mesmo pixel mistura mais de um uso da terra, tornando o gráfico de usos da terra diferentes muito similares ou iguais (SILVA, MAGNONI, 2020). 
Figura 9 - Painel comparativo para visualização/extração de dados de evapotranspiração dos produtos MOD16A2 x FLDAS sob três diferentes usos da terra como descrito na Tabela 1. (1) gera a série nos três pontos para o MOD16A2 e (2) para o FLDAS.

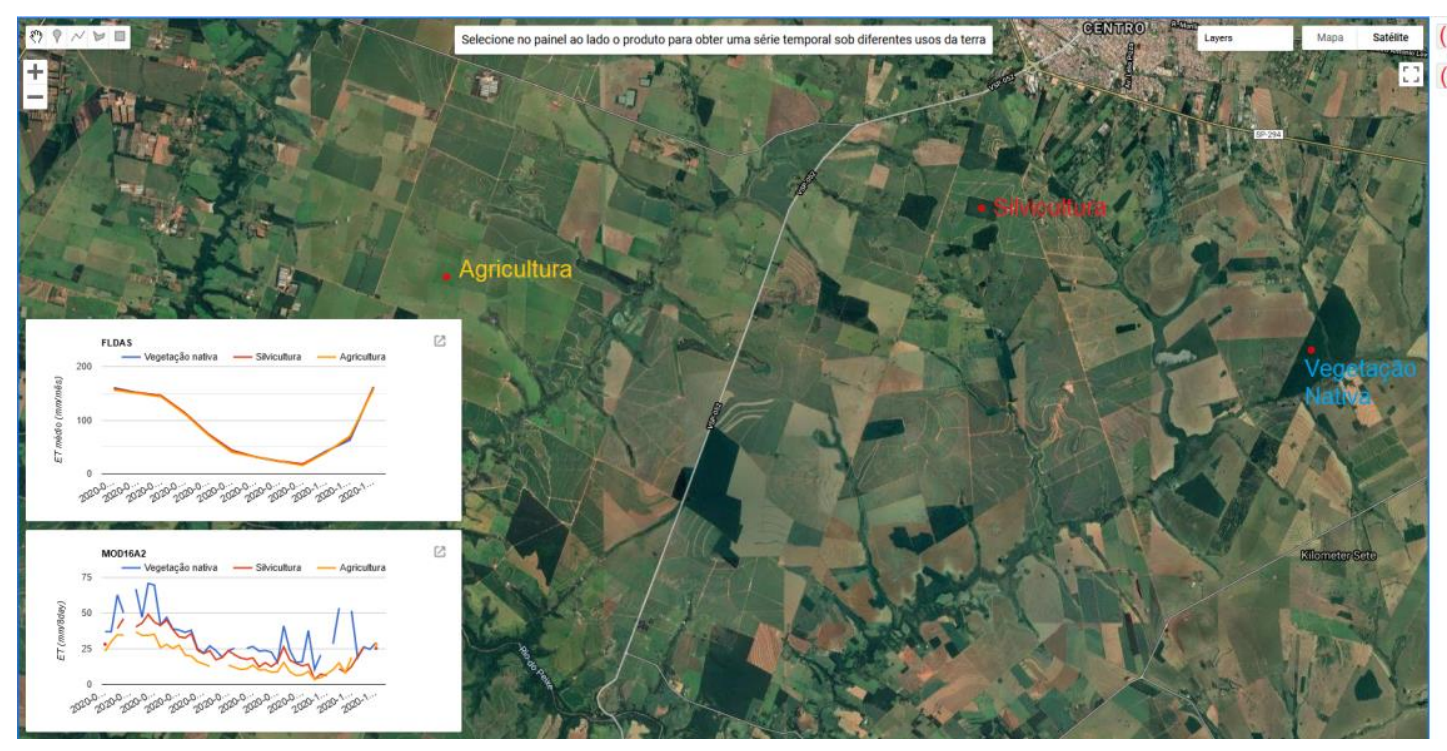

Figura 10 - Comparativo de séries temporais extraídas do painel P3 comparando resultados do MOD16A2 e FLDAS para o periodo de janeiro a dezembro de 2020 em três usos da terra
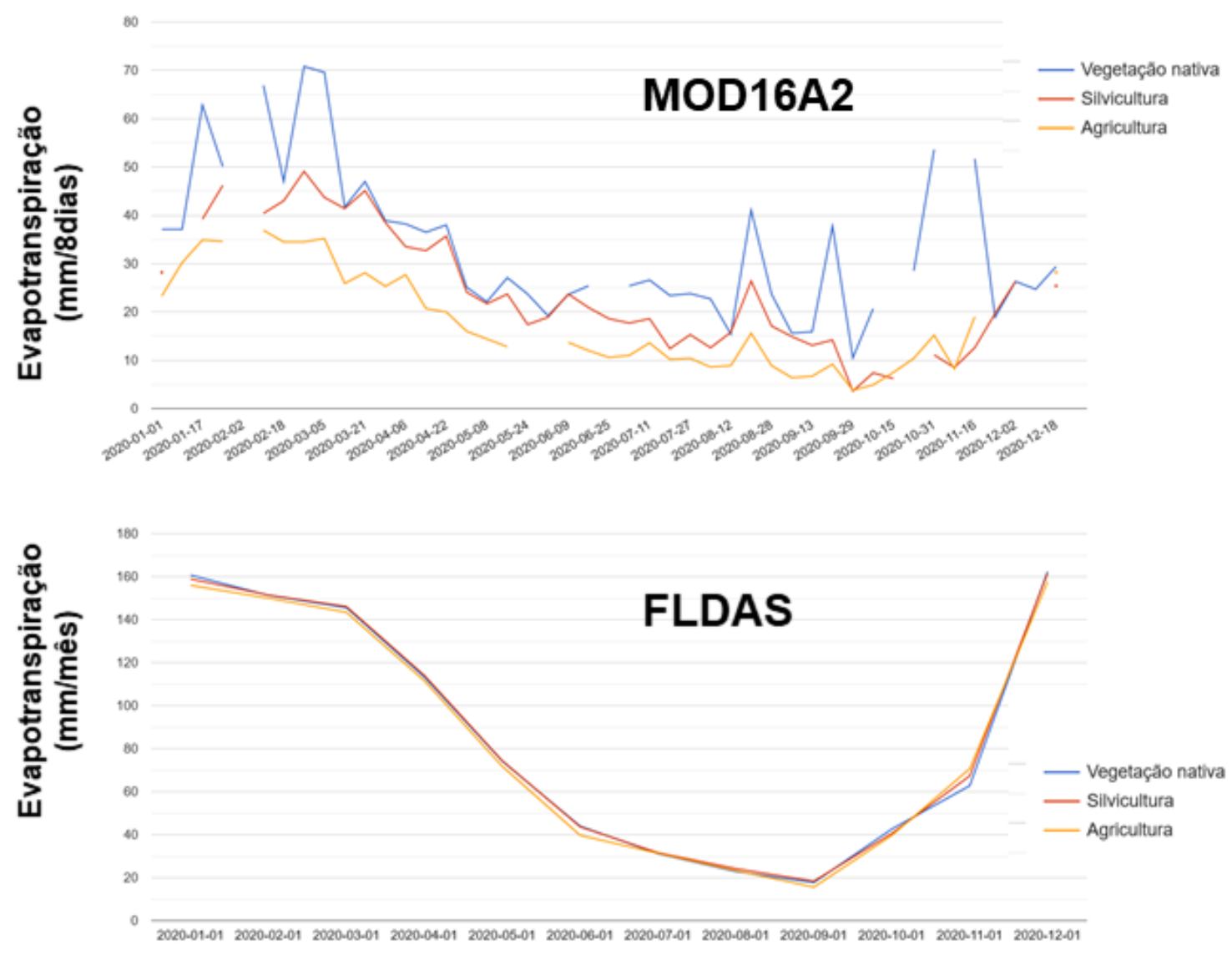
Nesse contexto, destacamos que a resolução espacial do FLDAS não é impeditivo para seu uso desde que seja aplicado, por exemplo, em estudos regionais, onde esse maior detalhamento não seja requerido. Também ressaltamos que sua larga faixa temporal (quase 40 anos) é um diferencial que deve ser aproveitado em estudos regionais. Enquanto o MOD16A2 é mais apropriado para estudos mais locais que requerem maior detalhamento espacial. Nota-se que há falhas nas linhas do MOD16A2 devido a intervalos com falta de dados, possivelmente por cobertura de nuvem que impossibilita a modelagem.

Apesar das diferenças de resolução espaço-temporal, observa-se que ambos os produtos apresentam uma tendência semelhante ao longo do período de 2020, onde os picos evapotranspirativos são mais frequentes nas épocas mais chuvosas e quentes do ano, que consequentemente apresentam mais água para ser evapotranspirada. De forma geral, as resoluções de um produto de sensoriamento remoto devem ser consideradas pelos usuários como fatores importantes na decisão sobre qual base de dados utilizar, sendo elas limitantes ou não limitantes ao seu uso dependendo do problema em questão.

\section{CONCLUSÕES}

O sensoriamento remoto permite a geração de séries espaço-temporais de variáveis essenciais ao manejo da agricultura irrigada e o monitoramento de variáveis biofísicas, principalmente, onde os recursos são limitados e pouca informação in situ é acessível. Isso permite o gerenciamento espacializado do uso da água, sendo a evapotranspiração um dos parâmetros mais complexos, porém mais estudados no contexto das modelagens com sensoriamento remoto.

Atualmente diferentes produtos/modelos baseados em estimativas por sensoriamento remoto encontram-se disponíveis e mais facilmente acessáveis por usuários finais na plataforma de computação na nuvem GEE, foi possível extrair dados de bases de dados de $E T_{A}$ por meio do GEE de forma facilitada, por meio de painéis interativos desenvolvidos pelos autores. O desafio de desenvolver a programação no ambiente do GEE é relativamente baixo frente ao custo computacional e "horas-pesquisador" envolvido em trabalhos de modelagem pelos métodos convencionais (que envolvem vários processos já pré-processados pelo GEE). Nesse sentido, o conhecimento em processamento digital, linguagens de programação e ciência de dados serão conhecimentos cada vez mais 
presentes no cotidiano dos pesquisadores que abordem o estudo da variabilidade da evapotranspiração em estudos ambientais e/ou agronômicos.

\section{REFERÊNCIAS}

ABATZOGLOU, J.T.; S.Z. DOBROWSKI, S.A.; PARKS, K.C. HEGEWISCH. TerraClimate, a high-resolution global dataset of monthly climate and climatic water balance from 19582015. Scientific data, 5: 170191, 2018.

ADORNO, B. V.; BARREIRA, S.; FERREIRA, M. E.; VELOSO, G. A.. Influence of native and exotic tree plantations on biophysical indicators in the Brazilian Savanna. Pesquisa Agropecuária Tropical, 51: e65815, 2021.

ALLEN R.G., TASUMI M., TREZZA R. Satellite-based energy balance for mapping evapotranspiration with internalized calibration (METRIC) model. Journal of Irrigation and Drainage Engineering, 133: 380-394, 2005.

ALLEN, R. G.; MORTON, C.; KAMBLE, B.; KILIC, A.; HUNTINGTON, J.; THAU, D.; GORELICK, S.; ERICKSON, T.; MOORE, R.; TREZZA, R.; RATCLIFFE, I.; ROBISON, C. EEFlux: A Landsat-based Evapotranspiration mapping tool on the Google Earth Engine. Emerging Technologies for Sustainable Irrigation -A Tribute to the Career of Terry Howell, Sr. Conference Proceedings. Anais... In: 2015 ASABE / IA IRRIGATION SYMPOSIUM. American Society of Agricultural and Biological Engineers, 10 nov. 2015. Disponível em: $<$ http://elibrary. asabe.org/abstract.asp?aid=46446\&t=3\&dabs=Y\&redir=\&redirType=>. Acesso em: 01 ago. 2021

ALLEN, R. G.; PEREIRA, L. S.; RAES, D.; SMITH, M. Crop evapotranspiration: guidelines for computing crop water requirements. FAO, Irrigation and Drainage Paper, 56. Roma, 1998. 300p.

ALLEN, R.G., M. TASUMI, R. TRESSA. Satellite-based energy balance for mapping evapotranspiration with internalized calibration (METRIC)-Applications. Journal of Irrigation and Drainage Engineering, 133(4): 395-406, 2007a. 
ALLEN, R.G., M. TASUMI, R. TREZZA. Satellite-based energy balance for mapping evapotranspiration with internalized calibration (METRIC)-Model. Journal of Irrigation and Drainage Engineering, 133(4): 380-394, 2007b.

AGÊNCIA NACIONAL DE ÁGUAS (ANA). Estimativas de evapotranspiração real por sensoriamento remoto no Brasil. 2020. Disponível em:

<http://www.snirh.gov.br/portal/snirh/centrais-de-conteudos/central-de-publicacoes/23estimativas-de-evapotranspiracao-real-por-sensoriamento-remoto>. Acesso em: 1 ago. 2021.

ARAUJO, L. M.; TEIXEIRA, A. H. C.; BASSOI, L. H. Evapotranspiration and biomass modelling in the Pontal Sul Irrigation Scheme. International Journal Remote Sensing, 1:1-13, 2019.

BASTIAANSSEN, W. G. M.; MENENTI, M.; FEDDES, R. A.; HOLTSLAG, A. M. A remote sensing surface energy balance algorithm for land (SEBAL). 1. Formulation. Journal of Hydrology, 212-213(1-4): 198-212. 1998a.

BASTIAANSSEN, W. G. M.; PElGRUM, H.; WANG, J.; MORENO, J. F.; ROERINK, G. J.; WAL, T. V. A remote sensing surface energy balance algorithm for land (SEBAL). 2. Validation. Journal of Hydrology, 212-213(1-4): 213-229. 1998b.

BEAUDOING, H.; RODELL, M.; NASA/GSFC/HSL. GLDAS Noah Land Surface Model L4 3 hourly 0.25 x 0.25 degree V2.1, Greenbelt, Maryland, USA, Goddard Earth Sciences Data and Information Services Center (GES DISC). 2020a. Disponível em:< https://disc.gsfc.nasa.gov/datasets/GLDAS_NOAH025_3H_2.1/summary>. Acesso em: 01 ago. 2021.

BERTONI, J.; LOMBARDI NETO, F. Conservação do solo. São Paulo: Ícone, 6ª Ed. 2014. $156 \mathrm{p}$.

CHRISTOFOLETTI, A. Modelagem de Sistemas Ambientais. São Paulo: Edgard Blücher, 1999. 236 p. 
COAGUILA, D. N. ; HERNANDEZ, F. B. T. ; TEIXEIRA, A. H. C. ; FRANCO, R. A. M.; LEIVAS, J. F. Water productivity using SAFER - Simple Algorithm for Evapotranspiration Retrieving in watershed. Revista Brasileira de Engenharia Agrícola e Ambiental, 21(7): 524-529, 2017.

EBITA, A.; KOBAYASHI, S.; OTA, Y.; MORIYA, M.; KUMABE, R.; ONOGI, K.; HARADA, Y.; YASUI, S.; MIYAOKA, K.; TAKAHASHI, K.; KAMAHORI, H.; KOBAYASHI, C.; ENDO, H.; SOMA, M.; OIKAWA, Y.; ISHIMIZU, T. Japanese 55-year reanalysis "JRA-55": an interim report. Sola, 7: 149-152, 2011.

FILGUEIRAS, R.; MANTOVANI, E. C.; ALTHOFF, D.; RIBEIRO, R. B.; VENANCIO, L. P.; SANTOS, R. A. Dynamics of actual crop evapotranspiration based in the comparative analysis of SEBAL and METRIC-EEFLUX. Irriga, 1(1): 72-80, 2019.

FIORIO, P. R.; COELHO, R. D.; BARROS, P. P. S.; BONILLA, M. Z.; GADY, A. P. B. Comportamento espectral de folhas da cana-de-açúcar na presença de déficit hídrico. Irriga, 23(3): 609-621, 2018.

FORMAGGIO, A. R.; SANCHES, I. D. Sensoriamento remoto em agricultura. São Paulo: Oficina de Textos, 2017. 256 p.

HARRIS, I.; OSBORN, T. J.; JONES, P.; LISTER, D. Version 4 of the CRU TS monthly high-resolution gridded multivariate climate dataset. Scientific data, 7(1): 1-18, 2020.

HEALY, R. W. Estimating groundwater recharge. Cambridge: Cambridge University Press, 2010. 245 p.

HEALY, R. W.; COOK, P. G. Using groundwater levels to estimate recharge. Hydrogeology Journal, 10(1): 91-109, 2002. 
HERNANDEZ, F. B. T.; TEIXEIRA, A. H. C.; NEALE, C. M. U.; TAGHVAEIAN, S.

Determining large scale actual evapotranspiration using agro-meteorological and remote sensing data in the northwest of Sao Paulo state, Brazil. Acta Horticulturae, 1038:263$270,2014$.

HONG, S., HENDRICKX, J. M., ALLEN, R. G. Comparison of Remote Sensing Energy Balance Models: Sebal V.S. Metric. AGU Fall Meeting Abstracts, H43G-1094, 2008.

JAWAK, S.D.; DEVLIYAL, P.; LUIS, A.J. A Comprehensive Review on Pixel Oriented and Object Oriented Methods for Information Extraction from Remotely Sensed Satellite Images with a Special Emphasis on Cryospheric Applications. Advances in Remote Sensing, 4: 177-195, 2015.

JENSEN, J. R. Remote sensing of vegetation. In. Remote sensing of the environment, an earth resource perspective. Upper Saddle River: Prentice Hall, 2000. p. 333-377.

KING, A.C.; RAIBER, M.; COX, M.E.; CENDÓN, D.I. Comparison of groundwater recharge estimation techniques in an alluvial aquifer system with an intermittent/ephemeral stream (Queensland, Australia). Hydrogeology Journal, 5(1): 1-19, 2017.

MAGNONI, P.H.J.; SILVA, C.O.F.; MANZIONE, R.L. Groundwater recharge and water table levels modelling using remotely sensed data and cloud-computing. Sustainable Water Resources Management, 6(6): 1-16, 2020.

MCNALLY A.; NASA/GSFC/HSL. FLDAS Noah Land Surface Model L4 Global Monthly $0.1 \times 0.1$ degree (MERRA-2 and CHIRPS). Greenbelt, MD, USA, Goddard Earth Sciences Data and Information Services Center (GES DISC). 2018. Disponível em:<https://disc.gsfc.nasa.gov/datasets/FLDAS_NOAH01_C_GL_M_001/summary>. Acesso em: 1 ago. 2020.

MCNALLY, A.; ARSENAULT, K.; KUMAR, S.; SHUKLA, S.; PETERSON, P.; WANG, S.; FUNK, C.; PETERS-LIDARD, C. D.; VERDIN, J. P. A land data assimilation system for sub-Saharan Africa food and water security applications. Scientific data, 4(1): 1-19, 2017. 
MENESES, P. R.; ALMEIDA, T.; BAPTISTA, G. M. M. Reflectância dos materiais terrestres. São Paulo: Oficina de Textos, 2019.

MINHONI, R. T. A.; PINHEIRO, M. P. M. A.; FILGUEIRAS, R.; ZIMBACK, C. R. L. Sensoriamento remoto aplicado ao monitoramento de macrófitas aquáticas no Reservatório de Barra Bonita, SP. Irriga, 22(2): 330-342, 2017.

MONTEITH, J.L. Evaporation and environment. Symposium of the Society for Experimental Biology, 19: 205-234, 1965.

MU, Q.; ZHAO, M.; RUNNING, S. W. Improvements to a MODIS global terrestrial evapotranspiration algorithm. Remote Sensing of Environment, 115(8): 1781-1800, 2011.

MU, Q.; HEINSCH, F.A.; ZHAO, M.; RUNNING, S.W. Development of a global evapotranspiration algorithm based on MODIS and global meteorology data. Remote Sensing of Environment, 111: 519-536, 2007.

NASA. The Landsat Program. NASA, 2019a. Disponível em:

<http://landsat.gsfc.nasa.gov/>. Acesso em: 1 ago. 2021.

NASA. The MODIA Program. NASA, 2019a. Disponível em: <https://modis.gsfc.nasa.gov/>. Acesso em: 1 ago. 2021.

ELNASHAR, A..; WANG, L.; WU, B.; ZHU, W.; ZENG, H. Synthesis of global actual evapotranspiration from 1982 to 2019 . Hydrology and Earth Scientifical Data, 13: 447480, 2021.

RAMOELO, A.; MAJOZI, N.; MATHIEU, R.; JOVANOVIC, N.; NICKLESS, A.; DZIKITI, S. Validation of Global Evapotranspiration Product (MOD16) using Flux Tower Data in the African Savanna, South Africa. Remote Sensing, 6: 7406-7423, 2014. 
ONOGI, K.; TSUTSUI, J.; KOIDE, H.; SAKAMOTO, M.; KOBAYASHI, S.; HATSUSHIKA, H.; MATSUMOTO, T.; YAMAZAKI, N.; KAMAHORI, H.; TAKAHASHI, K.; KADOKURA, S.; WADA, K.; KATO, K.; OYAMA, R.; OSE, T.; MANNOJI, N.; TAIRA, R. The JRA-25 reanalysis. Journal of the Meteorological Society of Japan. Ser. II, 85(3): 369-432, 2007.

PEIXOTO, D. W. B.; GUASSELLI, L. A.; PEREIRA FILHO, W. Estimativa de concentração de sedimentos em suspensão a partir de imagens Landsat 8 em PCHs no rio Ivaí-RS. Revista de Geociências - UNESP, 37(1): 147 - 154, 2018.

POLLO, R. A.; SILVA, C. O. F.; CARDOSO, L. G.; LESSA, L. G. F. Fatores de perturbação identificados em área de proteção ambiental Corumbataí-Botucatu-Tejupá, perímetro Botucatu, estado de São Paulo. Raega-O Espaço Geográfico em Análise, 46(1): 204-214, 2019.

PONZONI, F.J., SHIMABUKURO, Y.E. Sensoriamento remoto da vegetação. São Paulo, Oficina de Textos, 2010. 128 p.

REYNOLDS, C. A.; JACKSON, T. J.; RAWLS, W. J. Estimating soil water-holding capacities by linking the Food and Agriculture Organization soil map of the world with global pedon databases and continuous pedotransfer functions. Water Resources Research, 36(12): 3653-3662, 2000.

RODELL, M.; HOUSER, P. R.; JAMBOR, U.; GOTTSCHALCK, J.; MITCHELL, K.; MENG, C. -J.; ARSENAULT, K.; COSGROVE, B.; RADAKOVICH, J.; BOSILOVICH, M.; ENTIN, J. K.; WALKER, J. P.; LOHMANN, D.; TOLL, D. The global land data assimilation system. Bulletin of the American Meteorological Society, 85(3): 381-394, 2004.

RODELL, M. GLDAS: Project Goals. NASA, 2020. Disponível em: <https://ldas.gsfc.nasa.gov/gldas>. Acesso em: 1 ago. 2021. 
SANTOS, J. E. O.; CUNHA, F. F.; FILGUEIRAS, R,.; SILVA, G.H.; TEIXEIRA, A. H. C.; SILVA, F. C. S.; SEDIYAMA, G. C. Performance of SAFER evapotranspiration using missing meteorological data. Agricultural Water Management, 233:1-8, 2020.

SENAY, G.B.; BOHMS, S.; SINGH, R.K.; GOWDA, P.H.; VELPURI, N. M. et al. Operational evapotranspiration mapping using remote sensing and weather datasets: a new parameterization for the SSEB approach. Journal of the American Water Resources Association, 49: 577- 591, 2013.

SENAY, G.B.; FRIEDRICHS, M.; SINGH, R.K.; VELPURI, N.M. Evaluating Landsat 8 evapotranspiration for water use mapping in the Colorado River basin. Remote Sensing of Environment, 185: 171-185, 2016.

SENAY, G. B. Landsat-based illustrative implementation of Satellite Psychrometry for ET Mapping. U.S. Geological Survey data release, 2018. Disponível em:

$<$ https://www.usgs.gov/core-science-systems/nli/landsat/landsat-provisional-actualevapotranspiration/>. Acesso em: 1 ago. 2021.

SHAW, G.A.; BURKE, H.-H.K. Spectral Imaging for Remote Sensing. Lincoln Laboratory Journal, 14(1): 3-28, 2003.

SHIA, C.; WANGA, L. Incorporating spatial information in spectral unmixing: A review. Remote Sensing of Environment, 149: 70-87, 2014.

SHIMABUKURO, Y.E.; SMITH, J.A. The least-squares mixing models to generate fraction images derived from remote sensing multispectral data. IEEE Transactions on Geoscience and Remote Sensing, 29(1): 16-20, 1991.

\section{SILVA, C.O.F. Modelagem espacial da recarga das águas subterrâneas sob} diferentes usos e coberturas da terra. Dissertação (Mestrado em Agronomia: Irrigação e Drenagem) - Faculdade de Ciências Agronômicas, Universidade Estadual Paulista “Júlio de Mesquita Filho”. Botucatu, p. 200. 2019. 
SILVA, C. O. F.; MANZIONE, R. L.; ALBUQUERQUE FILHO, J. L. Large-scale spatial modeling of crop coefficient and biomass production in agroecosystems in southeast Brazil. Horticulturae, 4(4): 1-20, 2018a.

SILVA, C. O. F.; MANZIONE, R. L.; TEIXEIRA, A. H. C.. Modelagem espacial da evapotranspiração e produtividade hídrica na porção paulista do afloramento do aquífero Guarani entre 2013 e 2015. Holos Environment, 18(2): 126-140, 2018b

SILVA, C. O. F.; TEIXEIRA, A. H. C.; MANZIONE, R. L. Agriwater: An R package for spatial modelling of energy balance and actual evapotranspiration using satellite images and agrometeorological data. Environmental Modelling \& Software, 120: 104497, 2019a.

SILVA, C. O. F.; MANZIONE, R. L.; ALBUQUERQUE FILHO, J. L. Combining remotely sensed actual evapotranspiration and GIS analysis for groundwater level modeling. Environmental Earth Sciences, 78(15): 462, 2019b.

SILVA, C. O. F.; MANZIONE, R. L.; ALBUQUERQUE FILHO, J. L. Comparison of SAFER and METRIC-based actual evapotranspiration models in a subtropical area of BRAZIL. Irriga, 1(1): 48-55, 2019c.

SILVA, C. O. F.; MANZIONE, R. L. Dinâmica do uso e ocupação da terra na área de proteção ambiental "cuesta" - perímetro Botucatu, SP entre 2000 e 2016 . GEOUSP Espaço e Tempo, 23(1): 198-214, 2019d.

SILVA, C. O. F.; MATULOVIC, M.; MANZIONE, R. L. New dilemmas, old problems: advances in data analysis and its geoethical implications in groundwater management. Springer Nature Applied Sciences, 3(6): 1-17, 2021.

SILVA, C. O. F.; MEDEIROS, G. A. Avaliação ambiental e morfométrica da bacia do rio Jundiaí-Mirim: diagnósticos e subsídios para gestão ambiental. Boletim Campineiro de Geografia, 7(2): 441-454, 2017. 
SILVA, C. O. F.; MAGNONI, P. H. J. Modelagem Espacializada da Evapotranspiração Real em Área de Reflorestamento por meio do pacote agriwater em Ambiente R. In: Écio Souza Diniz; Pedro Manuel Villa. (Org.). Aplicações da Linguagem R em Análises de Vegetação. Ponta Grossa: Atena Editora, p. 82-95, 2020.

SILVA, F.; PESTANA, A.; MARTINS, L. Sensoriamento remoto para detecção de queimadas no cerrado maranhense: uma aplicação no Parque Estadual do Mirador. Revista de Geografia Acadêmica, 13(2): 90-105, 2019.

TATEISH, R., AHN, C.H., Mapping evapotranspiration and water balance for global land surfaces. ISPRS Journal of Photogrametry \& Remote Sensing, 51: 209-215, 1996.

TEIXEIRA, A.H, C, BASTIAANSSEN, W.G.M., AHMAD, M.D., MOURA, M.S.B., BOS, M.G. Analysis of energy fluxes and vegetation-atmosphere parameters in irrigated and natural ecosystems of semi-arid Brazil. Journal of Hydrology, 362: 110-127, 2008.

TEIXEIRA, A.H.C. Determining regional actual evapotranspiration of irrigated and natural vegetation in the São Francisco River basin (Brazil) using remote sensing an PenmanMonteith equation. Remote Sensing, 2: 1287-1319, 2010.

TEIXEIRA, A. H. C.; SCHERER-WARREN, M.; HERNANDEZ, F.B.T.; ANDRADE, R.G.; LEIVAS, J.F. Large-Scale Water Productivity Assessments with MODIS Images in a Changing Semi-Arid Environment: A Brazilian Case Study. Remote Sensing, 5: 57835804, 2013.

TEIXEIRA, A. H. C.; PADOVANI, C. R.; ANDRADE, R. G.; LEIVAS, J. F.; VICTORIA, D. DE C.; GALDINO, S. Use of MODIS images to quantify the radiation and energy balances in the Brazilian Pantanal. Remote Sensing, 7: 14597-14619, 2015a.

TEIXEIRA, A.H. de C., HERNANDEZ, F.B.T., ANDRADE, R.G., LEIVAS, J.F., VICTORIA, D. de C. BOLFE, E.L. Corn Water Variables Assessments from Earth Observation Data in the São Paulo State, Southeast Brazil. Journal of Hydraulic Engineering, 1: 1-11, 2015b. 
TEIXEIRA, A. H. C.; LEIVAS, J. F.; RONQUIM, C. C.; SILVA, G. B.; VICTORIA, D. de C. Energy balances in sugar cane, coffee and natural vegetation in the northeastern side of the São Paulo state, Brazil. Proceedings of SPIE, 9998: 99980M-1 - 99980M-16, 2016.

TEIXEIRA, A. H. C.; REIS, J. B. R. S.; LEIVAS, J. F.; SILVA, G. B.; STRUIVING, T. B. Componentes da produtividade da água modelados por sensoriamento remoto em limoeiros irrigados de Minas Gerais. Agrometeoros, 25: 237-247, 2017.

THORNTHWAITE, C. W. An approach toward a rational classification of climate. Geographical Review, 38: 5 5-94, 1948.

TUCCI, C. E. M.; SILVEIRA A. L. L.; Hidrologia: ciência e aplicação. Porto Alegre, $4^{\circ}$ Ed. UFRGD/ABRH, 2015. 944 p.

USGS - United States Geological Survey. The Landsat Program. Washington, DC, 2013. Disponível em: <http://landsat.gsfc.nasa.gov/>. Acesso: 1 ago. 2021.

VAN DER WERFF, H.; VAN DER MEER, F. Sentinel-2 for Mapping Iron Absorption Feature Parameters. Remote Sensing, 7: 12635-12653, 2015.

VERDIN, K.L., GREENLEE, S.K., 1996. Development of continental scale digital elevation models and extraction of hydrographic features. In: Proceedings, Third International Conference/Workshop on Integrating GIS and Environmental Modeling, Santa Fe, New Mexico, 1996.

WANG-ERLANDSSON, L., BASTIAANSSEN, W. G. M., GAO, H., JÄGERMEYR, J., SENAY, G. B., VAN DIJK, A. I. J. M., GUERSCHMAN, J. P., KEYS, P. W., GORDON, L. J., AND SAVENIJE, H. H. G.: Global root zone storage capacity from satellite-based evaporation. Hydrology and Earth System Sciences, 20: 1459-1481, 2016.

WESTERHOFF, R. S. Using uncertainty of Penman and Penman-Monteith methods in combined satellite and ground-based evapotranspiration estimates. Remote Sensing of Environment, 169: 102-112, 2015. 
WORDCLIM. Downscaling future and past climate data from GCMs. Disponível em: https://www.worldclim.org/data/downscaling.html. Acesso em: 1 ago. 2021. 


\begin{abstract}
The objective of this review article was to compile the theoretical and technological aspects of remote sensing-based evapotranspiration (ET) modeling. We surveyed the thermohydrological concepts that support the ET phenomenon, such as soil energy fluxes ("thermo") and hydrological balance. We also present the main variants of the ET concept. We survey the most disseminated models applied to satellite imagery (to be implemented by the researcher) and present their assumptions, limitations, and opportunities. Models based on remote sensing focus on the actual ET. Finally, we surveyed ready-made actual ET databases (available on Google Earth Engine - GEE), and for these, we developed interactive panels, for data extraction. With these panels, it is possible to easily extract actual ET time series and perform subsequent calibrations with field data.
\end{abstract}

Keywords: Agrometeorology. Hydrology. Google Earth Engine. Modeling. Automation.

\title{
RESUMEN
}

El objetivo de este artículo de revisión era recopilar los aspectos teóricos y tecnológicos de la modelización de la evapotranspiración (ET) basada por teledetección. Hemos estudiado los conceptos termohidrológicos que subyacen al fenómeno de la ET, a saber, los flujos de energía en el suelo ("térmo") y el balance hidrológico. También presentamos las principales variantes del concepto de ET. Hacemos un repaso de los modelos más extendidos aplicados a las imágenes de satélite (para que el investigador los aplique) y presentamos sus supuestos, limitaciones y oportunidades. Los modelos basados en la teledetección se centran en la ET real. Por último, hemos estudiado bases de datos de ET real ya hechas (disponibles en Google Earth Engine - GEE), y para ellas hemos desarrollado paneles interactivos para la extracción de datos. Con estos paneles es posible extraer fácilmente las series temporales de la ET real y realizar calibraciones posteriores con datos de campo.

Palabras-clave: Agrometeorología. Hidrología. Google Earth Engine. Modelización. Automatización. 


\section{LICENÇA DE USO}

Este é um artigo publicado em acesso aberto (Open Access) sob a licença Creative Commons Atribuição 4.0 Internacional (CC BY 4.0), que permite uso, distribuição e reprodução em qualquer meio, desde que o trabalho original seja corretamente citado. Mais informações em: http://creativecommons.org/licenses/by/4.0

\section{CONFLITO DE INTERESSES}

Os autores declaram que não há conflito de interesses neste trabalho.

\section{CONTRIBUIÇÕES AUTORAIS}

Autor 1: responsável pela condução da pesquisa exploratória e redação científica.

Autor 2: responsável pela condução da pesquisa exploratória e redação científica.

Autor 3: responsável pela revisão do manuscrito

\section{FINANCIAMENTO}

Os dois primeiros autores agradecem ao Conselho Nacional de Desenvolvimento Científico e Tecnológico (CNPq) pela concessão de bolsas de mestrado.

\section{AGRADECIMENTO}

Os dois primeiros autores agradecem ao Conselho Nacional de Desenvolvimento Científico e Tecnológico (CNPq) pela concessão de bolsas de mestrado. Os autores agradecem também aos avaliadores presentes nas bancas de defesa de mestrado que contribuíram na melhoria do texto das dissertações de mestrados dos dois primeiros autores.

\section{COMO REFERENCIAR}

SILVA, César de Oliveira Ferreira; MAGNONI, Pedro Henrique Jandreice; MANZIONE, Rodrigo Lilla. Sensoriamento remoto orbital para modelagem da evapotranspiração: síntese teórica e aplicações em computação na nuvem. Revista Brasileira de Engenharia de Biossistemas (Tupã), v. 15, n. 3, p. 425-468, 2021. DOI: http://dx.doi.org/10.18011/bioeng2021v15n3p425-468.

\section{RESPONSABILIBADE EDITORIAL}

Prof. Dr. Fernando Ferrari Putti ${ }^{1}$, Prof. Dr. Paulo Sérgio Barbosa dos Santos ${ }^{1}$, Prof. Dr. Eduardo Festozo Vicente ${ }^{1}$ e Prof. Dr. Diogo de Lucca Sartori ${ }^{1}$

1 Universidade Estadual Paulista "Júlio de Mesquita Filho", FCE - Faculdade de Ciências e Engenharia, Tupã, SP, Brasil. 